\title{
The Role for Pre-Polymerized Sucralfate in Management of Erosive and Non-Erosive Gastroesophageal Reflux Disease - High Potency Sucralfate-Mucin Barrier for Enteric Cytoprotection
}

\author{
Ricky Wayne McCullough ${ }^{1,2 *}$ \\ ${ }^{1}$ Translational Medicine Clinic and Research Center, USA \\ ${ }^{2}$ Department of Internal Medicine and Emergency Medicine, Warren Alpert Brown University School of Medicine, USA
}

*Corresponding author: Ricky Wayne McCullough, Translational Medicine Clinic and Research Center, Storrs Connecticut, USA.
Received Date: April 13, 2020

Published Date: April 22, 2020

\begin{abstract}
Clinical outcomes from standard sucralfate do not justify a role in the management of erosive and non-erosive gastroesophageal reflux disease. Pre-polymerized sucralfate, sometimes called high potency sucralfate or polymerized cross-linked sucralfate is a new sucralfate formulation recognized by the US FDA in 2005. Positive clinical data from three randomized controlled trials using pre-polymerized sucralfate for GERD and NERD was first reported in 2014 AGA's Digestive Disease Week (DDW). Gastric refluxate contains protonic acid, dissolved bile acids and proteases each of which cause classic mucosal reactions in the esophageal epithelium. These reactions are symptomatic but may or may not involve erosions. Pre-polymerized sucralfate utilizes biophysical means to exclude all three irritants from epithelial mucosa.

Being non-systemic, the entire clinical effect of any sucralfate rests in the surface concentration of sucralfate achieved. Pre-polymerized sucralfate, presented in 2014 DDW, and discussed here, achieves a surface concentration that is $800 \%$ greater than standard sucralfate on normal mucosal lining and 2,400\% greater on inflamed or acid-injured mucosa, making it most certainly, a high potency sucralfate. To understand the biomolecular basis of its clinical effect, this review re-introduces the reader to mucosal barrier, discloses the exact site of engagement of sucralfate (mucin within the mucous gel), and how transient sucralfate-mediated biostructural changes in extra-cellular mucin is translated into intra-cellular signaling that modules the mucosal reaction to refluxate. This represents significant enteric cytoprotection.. A broad-based literature review will not only aid understanding of the molecular basis of sucralfate's clinical effects but will also provide context for an informed impression of whether pre-polymerized sucralfate has a role in the management of GERD and NERD.
\end{abstract}

Keywords: Polymerized sucralfate; NERD; GERD; Regulatory dichotomy

\section{Review: A Role for Pre-Polymerized Sucralfate} in the Management of Erosive and Non-erosive Gastroesophageal Reflux Disease

The superior performance of acid-controlling therapies, namely proton pump inhibitors (PPI) and histamine-2 receptor antagonists (H2RA), eroded the early but tenuous role of sucralfate in the treatment of gastroesophageal reflux disease (GERD), which role had resulted from clinical off-labeled use of sucralfate's original regulatory indication, wihch was the management of duodenal ulcers. The clinical performance of standard sucralfate dosed at $14 \mathrm{mg}$ per $\mathrm{kg}$ (1 gram) four times daily was clinically inconsistent, substantially unimpressive and led to its exclusion from most clinical guidelines for GERD [1-4]. Clinical efficacy for standard sucralfate, whether tablet or suspension, had been largely mediocre for both erosive GERD and for NERD, non-erosive gastroesophageal reflux disease. There were two notable exceptions - a trial conducted by Simon, et al. [5] in NERD patients using a mucoadherent gel formulation of sucralfate (twice as potent as sucralfate suspension in terms of retention on the mucosal lining of the gastrointestinal (GI) tract [6,7]) and a trial conducted by Vermieidien, et al. [8] using sucralfate suspension for eGERD. In the former study [5], a 14mg/ 
$\mathrm{kg}$ dose of sucralfate gel (1gram) given twice daily for 42 days resulted in symptom relief for $71 \%$ of NERD patients compared to $29 \%$ taking placebo. In the latter study [8], a similar dose of sucralfate suspension ( 1 gram) given four times daily for 56 days resulted in symptomatic relief in $72 \%$ of eGERD patients with a corresponding healing rate of $68 \%$. Given that sucralfate works by coating the mucosa [9], a perception prevailed that its suspension form was better than the tablet which had to first dissolve in the stomach before coating, and by extension the gel form of sucralfate was assumed better than the suspension because of the mechanical retention of sucralfate coating $[6,7]$ by the gel. These perceptions implied that the formulation of administered sucralfate could be determinative of its clinical effect.

In 2005, the US Food and Drug Administration (FDA) recognized a new formulation sucralfate, pre-polymerized sucralfate [10], which it currently regulates as a medical device, a type of barrier therapy. Comparatively, low doses of pre-polymerized sucralfate suspension (1.5 gram bid versus 1 gram qid) unexpectedly demonstrated efficacy in both eGERD and NERD patients with 1 week $80 \%$ complete healing of eGERD and 4 week $83 \%$ reversal of symptomatic NERD [11]. Obviously, a review of any plausible role of sucralfate in the management of eGERD and NERD requires an understanding of how a new medicinal formulation, namely prepolymerization, results in improved and enhanced clinical function. This review will highlight specific data from three randomized controlled trials that used low dose pre-polymerized sucralfate to achieve outsized treatment effects in undifferentiated NERD and in erosive GERD. The biological nature of all forms of reflux disease, and the common but specific pathophysiologic challenge it poses to a prospective intervention is important to appreciate. In short, the challenge to be addressed by pre-polymerized sucralfae is that there are at least three main irritants in gastric refluxate giving rise to two types of mucosal reactions. These facts are not commonly discussed in GERD or NERD guidelines nor do they receive attention proportionate to their role in creating disease, its symptoms and consequences.

\section{The Challenge of Reflux Disease - Several Irritants, Several Mucosal Reactions}

Whether erosive or non-erosive, the symptoms and signs of GERD arise from a mucosal reaction to the backwash of gastric refluxate. Physiologic reflux is asymptomatic, endoscopically normal, and presumably without histomorphological consequences [12]. Continuous manometric recordings of esophageal $\mathrm{pH}$ show that there are short episodes of acid reflux in the normal population generally following meals and not uncommonly at night when recumbent [13-15]. Early observations included the following: (a) complete absence of lower esophageal sphincter (LES) pressure was essential for reflux ; (b) at low LES any elevation of intrabdominal pressure increases frequency reflux events ; and (c) in asymptomatic recumbent subjects reflux is related to transient inappropriate LES relaxation rather than low steady-state basal LES pressure. Regardless of these observations, the mere occurrence of heartburn heralds a likely advent of histomorphologic changes.
According to Rome IV classification [16,17], symptomatic reflux is either erosive or non-erosive. Non-erosive heartburn associated with normal reflux frequency is known as esophageal reflux hypersensitivity syndrome [18]. Non-erosive heartburn that is unrelated to reflux episodes is termed functional heartburn. Nonerosive heartburn associated with abnormally frequent reflux is classic NERD as oppose to esophageal hypersensitivity or functional heartburn.

Symptom perception to acid and mucosal integrity are inextricably linked [19-21] and it so happens that whether a patient has erosive GERD, or either of the two functional NERD or classic NERD syndromes, symptomatic reflux is associated with some degree of histomorphologic alterations in the esophageal mucosa $[22,23]$. In essence, regardless of clinical phenotype, symptomatic heartburn signals a material breach of esophageal epithelium, if even the mucosal reaction is cytokine based and escapes gross visible changes in tissue appearance.

Regardless of tissue appearance by endoscopy, tissue biopsies reveal cellular alterations facilitated by reactionary immune events in the mucosa [24-27]. These events are effectuated by proinflammatory cytokines $[28,29]$ and present as dilated intercellular spaces within the esophageal epithelium [22,30]. Afferent innervation of the esophagus by the vagus nerve is a shared characteristic of all Rome IV GERD patients [31] and there are differential submucosal depths of neurosensory nociception, with afferent pain fibers being more shallow in the proximal esophagus [32]. Heartburn sensation arises from firing of sensory neurons in the distal esophagus and indicates a histochemical disturbance within the mucosa which excite submucosal nociceptors [33] and upregulate afferent neurons to release painful neurokinins and to elevate hyperalgesia by increasing the expression of nociceptors. Nociceptors are ion flux voltage gated receptors classified as acid sensing ion channels (ASIC) [34] and as transient receptor potential vanilloid receptors (TRPV) [35]. These receptors require continual transmucosal flux of ions (positive with negative ion exchange) to keep afferent neurons switched-on during GERD episodes.

The lack of symptom response in some GERD patients to PPI's, H2RA's and antacids imply existence of histochemical processes exclusive of $\mathrm{pH}$. In fact, observations that both $\mathrm{pH}$-responsive and pH-non-responsive NERD patients exhibit dilated intercellular spaces in the esophageal epithelium [22] and basal cell hyperplasia beyond that of controls [23], suggest that mucosal reaction in functional and classic NERD is not simply a problem of acid content $(\mathrm{pH})$ of gastric refluxate. Within gastric refluxate there are least three irritants that illicit pain, neuro-excitation and subepithelial (lamina proprial) cytokine inflammation - protonic acid, dissolved bile acid and proteases (trypsin, chymotrypsin, and pepsin). Dissolved conjugated bile is as culpable as acid [36-39], in causing intercellular dilation $[40,41]$. Bile acids elicit mast-cell mediated upregulation of pain receptors in the lower esophagus [42] as well as cytokine-driven inflammation from reflux [29]. These alterations in immuno-homeostasis and the associated histomorphology give rise to higher transepithelial permeability and lower extracellular 
impedance observed in the esophagus of patients with functional heartburn, GERD, and NERD [21].

In recumbent patients, mineral acid (hydrochloric acid) and bile reflux together $[39,43]$ and reflux events containing bile may be more numerous than reflux events of acid alone [44]. Dissolved bile acids, particularly taurine conjugates of cholic acid and chenodeoxycholic acid, [36,37] are not deterred by acid-controlling therapies, and there is evidence to suggest, that perhaps elevate pH may facilitate exposure to dissolved bile [38]. So both mineral acid and dissolved bile acids co-dependently and independently initiate pro-inflammatory immunologic processes [24,25,28,45] raising the question whether inflammatory cytokines rather than caustic acid actually creates symptomatic GERD $[29,46]$ In both erosive GERD, functional heartburn and classic NERD, the presence of reflux events (mixed acid and bile) increases the submucosal expression of interleukin-8 (IL-8), of TRPV1 for acid nociception and of nerve growth factor (NGF), which hypersensitizes afferent sensory nerve function $[47,48]$. In patients with NERD, the quantity of lower esophageal mast cells is nearly doubled compared to controls, and the percentage of degranulated mast cells is elevated as well, $27 \%$ versus $12 \%$, respectively [26]. Bile acids are known to trigger mast cell degranulation in the lamina propria which in turn induces visceral hypersensitivity (pain) through the postdegranulation release of nerve growth factor [42]. Serine proteases present in gastric refluxate also illicit mucosal immunoreactions. Typsin induces mucosal secretion of IL-8 impairing the epithelial barrier [49], negatively modulating tight junction proteins thus undermining mucosal integrity [50]. Trypsin injury elicits a 10 fold upregulation of the proteinase-activated receptor-2 (PAR-2) gene throughout the epithelial layers, which is associated with enhanced IL-8 expression, papillary elongation, basal cell hyperplasia, and dilated intercellular spaces in esophagus of patients with eGERD [51].

\section{Countering Exposure and Consequences of Recur- ring Refluxate}

Clearly, the physiologic cause of the symptom and signs of GERD, whether erosive or non-erosive, is recurrent exposure to gastric refluxate that contains protonic acid, dissolved bile acids and serine proteases. The mucosal immuno-reaction and subsequent histomorphologic alterations are a consequence of repeated physical exposure to gastric refluxate. Thus a reasonable therapeutic approach in management GERD would be interventions that physically deny gastric refluxate (and by extension its caustic contents) access to the mucosal lining of the esophagus. An esophageal coating agent such as pre-polymerized sucralfate could physically deny refluxate recurrent access to the underlying mucosa. The notion of a therapeutic esophageal coating is a pragmatic concept easy for patients to understand. But prescribing such a therapy requires practitioners to understand the medicinal chemistry, mode of action and regulatory background of pre-polymerized sucralfate as well as the dynamics of the 'terms of engagement' (so to speak) with its mucosal target. The 'terms of engagement' that sucralfate has with its mucosal target are the biophysical determinants of that target, how those determinants relate to the integrity of the mucosal barrier and are parlayed into observable clinical effects of sucralfate.

The concept that the sucralfate barrier is like an adhesive "bandaid" oversimplifies the parallel cascades of events put in motion by the coating action of pre-polymerized sucralfate on the mucus gel. A more nuanced understanding of events resulting from the coating action of pre-polymerized sucralfate, involves the functional physiology of an intact mucosal barrier as well as the medicinal chemistry of pre-polymerized sucralfate. To this point, and as will be discussed later, the mucosal barrier and its integrity is more than tight junction proteins, the presence or absence for dilated intercellular spaces. Rather, the mucosal barrier is comprised of three distinct histologic compartments, with their respective structural elements intertwine by at least seven interrelated and codependent physiologic functions that are distributed among the three compartments. Ultimately the homeostatic operation of the seven functions is protected by the corporeal integrity of the mucus gel compartment, which is the compartment targeted by the coating of pre-polymerized sucralfate.

Physical coating of pre-polymerized sucralfate thwarts access of the three main gastric irritants to the esophagus and simultaneously exerts a physiochemical order within the mucus gel which in turn is translated to the epithelium biophysically for the enterocyte to modulate processes of inflammation. Biophysical communication between mucin of the mucus gel and the esophageal epithelium is converted into intracellular communication controlling pivotal levers of inflammation. The concept of barrier therapy is simple, but the mechanics whereby barrier action is converted into clinical effects has gradation. Having described the challenge of reflux disease in terms of three chief causative irritants and the corresponding mucosal reactions to those irritants, this report turns to the history of sucralfate, its regulatory dichotomy, the medicinal chemistry of pre-polymerized sucralfate and the biological basis for its clinical actions. Any role in clinical guidelines for polymerized sucralfate would require this as a foundation. In covering the biological basis of sucralfate effect, an updated perspective of the mucosal barrier targeted by sucralfate will be provided. Covering the molecular basis of action, the report describes how the sucralfate-mucin engagement specifically denies refluxate access, creates immediate positive consequences from that denial and indirectly leads to epithelial signaling that is ultimately responsible for the positive clinical outcomes of sucralfate coating. A synopsis of the three randomized controlled trials provide published data supporting the conclusion that there may be a role for prepolymerized sucralfate in the management of GERD. But first this report begins with some background on sucralfate, its regulatory history, medicinal chemistry, and biological basis of action.

\section{History and Regulatory Dichotomy of Sucralfate}

\section{History of sucralfate}

Sucralfate is a synthetic analog of a unit of gastric mucin. Discovered in 1968, it represented the culmination of academic 
quests dating from $1772[52,53,54]$ - a quest to understand why the stomach did not digest itself. The 1907 theory of mucoprotection by gastric mucus, [55] sparked investigational interests in gastric mucus, with subsequent discovery of mucin and 'mucoids'. Efforts to decipher mucin's structure between 1911 [56] and 1918 [57] led researchers to concluded in 1920 that the theory of mucoprotection by gastric mucus was a fact [58]. The period from 1930's through the 1950's was subsumed with deciphering the physiologic performance of gastric mucin $[59,60]$, its clinical application for the treatment of peptic ulcer [61] and led to the discovery that the chondroitin sulfate fraction of mucin was pepsin-suppressing and mucoprotective [62]. Understanding matured regarding the gastric mucus barrier and its secretions from 1940 to 1950 [63-66] and studies on the therapeutic value of sulfonated polysaccharides projected from the 1950's into the late1960's [67-71]. Academic efforts in Japan expanded from sulfonated polysaccharides to sulfonated analogs of oligosaccharides (chain of three to nine sugars), disaccharides and monosaccharides. In 1966, this led to the synthesis of octasulfonated sucrose, whose aluminum hydroxide salt was called sucralfate [72].

\section{Regulatory history}

Full descriptions of its therapeutic properties [73] and published data from multi-centered clinical trials [74] resulted in the first regulatory approval of sucralfate for human use in Japan in 1968. The 1969 US Patent on sucralfate [75], was followed thirteen years later with the 1982 US FDA approved New Drug Application (NDA) \# 18333 [76] for sucralfate solid dose form (Carafate) to treat duodenal ulcers. This was followed in 1993 by US FDA approval of NDA\#19083 [77] a 10\% suspension of sucralfate for the treatment of duodenal ulcers. From 1993 to date there has been over 214 brands of sucralfate tablets, suspensions or powders formally regulated by more than 69 countries [78]. Sucralfate has a reputation for being a safe drug, associated with few adverse reactions and nonspecific absorption of concomitantly administered drugs that may electrostatically adhere to it. Despite widespread use, its favorable drug profile has remained unchanged since of its first approval in Japan [79]. Regulatory authorities in 13 countries have granted over-the-counter (OTC) status to sucralfate tablets, suspension and powders resulting in 1.67 billion people having access to sucralfate drug without pharmacist's or physicians' order. For the remaining 5.8 billion people, however, sucralfate remains by prescription only.

\section{Regulatory Dichotomy of Sucralfate as Medical Device- US FDA 2005 to 2013}

Whether in tablet, powder or suspension, each dose form of sucralfate is biologically inert and requires activation by gastric acid to polymerize into its clinically active form. This "chemical action" within the body, classifies standard sucralfate as a drug by all regulatory bodies. However, in 2005, the US FDA recognized a regulatory dichotomy for sucralfate. Their position was detailed in an Agency Product Designation Ruling known as an RFD, request for designation [10]. The RFD process involved a joint agency review of the original mechanism of action for sucralfate by the
Center for Drug Evaluation and Research (CDER) and the Center for Device and Radiological Health (CDRH). Sucralfate drug had been classified by the CDER as a non-systemic site protective agent requiring post-ingestion polymerization to selectively engage (coat) fibrinous debris and mucin [80,81]. In their RFD of 2005 [10], the FDA established a regulatory finding of fact that if sucralfate is polymerized before ingestion, or pre-polymerized, then it is a medical barrier device, having a physical mode of action and requiring no further chemical action to be clinical active. Since this clarification, the FDA has maintained two regulatory statuses for sucralfate - a status as a drug for non-polymerized sucralfate pre-packaged in its unpolymerized biologically inert form, and a status as a medical device for sucralfate pre-polymerized prior to patient use. In 2013, under the $510 \mathrm{~K}$ program of the CDRH, the FDA licensed the first commercially distributed pre-polymerized sucralfate barrier therapy medical devices. The suspension formulation of this pre-polymerized sucralfate (Esolgafate) has been studied in three randomized controlled trials.

\section{Medicinal Chemistry of Polymerized Sucralfate}

Sucralfate polymerization is simply ion-facilitated self-annealing of sucralfate. Without polymerization sucralfate cannot work. There are three main forms of polymerized or self-annealed sucralfate, water-polymerized (WP) sucralfate, gastric acid polymerized (GAP) sucralfate as type of mineral acid polymerization, and organic acid polymerized (OAP) sucralfate. WP sucralfate results when moisture partially dissolves solid dose form of sucralfate, tablet or powder rendering a 40-70\% concentration of sucralfate. Applying sucralfate powder or crushed sucralfate tablets to moisture (a moist wound) or to drops of water creates WP sucralfate. In concentrations that are less than $40 \%$ in WP sucralfate, competing hydrogen-bonding from water overrides sucralfate's ability to favor self-annealing. Exposure to gastric acid also polymerizes sucralfate. Original endoscopic examinations of sucralfate $[9,82]$ reveal partially dissolved/polymerized sucralfate adherent to the gastric mucosa as GAP sucralfate. It is more resistant to competing hydrogenbonding forces of water hydration. Non-gastric hydrochloric acid can be used to create mineral acid polymerized (MAP) sucralfate which was the subject of the RFD reviewed by the US FDA [10]. The use of organic acids to polymerize (OAP) sucralfate creates a more resilient amorphous polymerized compound. OAP sucralfate utilizes weak organic acids such as acetic acid to polymerized sucralfate. Pre-polymerized sucralfate used in the clinical trials utilized a cationic organic acid to effect polymerization. While WP, GAP and MAP are sensitive to water hydration, thereby more easily washed away, OAP is less sensitive to water hydration and thereby maintains longer physical presence on the mucosal lining.

Table 1 provides a qualitative perspective on the presence of polymerization and its weakness or vulnerability to disruptive hydration and dissolution by water. As the degree of polymerization increases, the vulnerability to disruptive dissolution diminishes. Once the surface concentration of sucralfate on the mucosal lining suffers a significant drop off, then the clinical effect of sucralfate is 
lost. Just as a 'gel' formulation of sucralfate remains mucoadherent for at least 1 hour following ingestion $[6,7]$, so too there is prolonged mucoadherence of pre-polymerized sucralfate and a subsequent enhanced muco-concentration of sucralfate. Figure 1 shows that 3 hours post-administration, this form of pre-polymerized sucralfate achieves and maintains a surface concentration of sucralfate that is 7 fold (or $800 \%$ ) greater on normal mucosa and 23 fold (or $2400 \%$ ) greater on acid-injured mucosa compared to gastricacid polymerized sucralfate [83]. Enhanced muco-retention was expected. But enhanced muco-concentration of sucralfate was not and is believed to occur post ingestion due to ionic preference of sucralfate polymerized by a weak organic acid; there is an in situ perpetuation of sucralfate self annealment. This suspected postingestion hyper-self-annealing in situ may occur in a manner similar to pi-stacking [84], a extra-molecular phenomenon where electrostatic substituents that have stereotactic mobility (ability to swivel, spin and flex out of plane while in a covalent bond) will selfattract and self-anneal in water. In essence non-covalently bonded sheets of sucralfate amass and self-assemble on the mucosal lining.

Table 1: Qualitative Degree and Strength of Polymerization.

\begin{tabular}{|c|c|}
\hline Sucralfate Entity & Degree of Polymerization \\
\hline Sucralfate tablet/powder (bio-inert) & None \\
\hline Sucralfate Suspension (bio-inert) & Minimal \\
\hline WP-Sucralfate (bio-inert) & Moderate \\
\hline GAP/MAP - Sucralfate & High \\
\hline OAP-Sucralfate & Extreme \\
\hline WP- Water Polymerization; GAP- Gastric Acid Polymerization; MAP- Mineral Acid Polymerization; OAP - Organic Acid Polymerization &
\end{tabular}

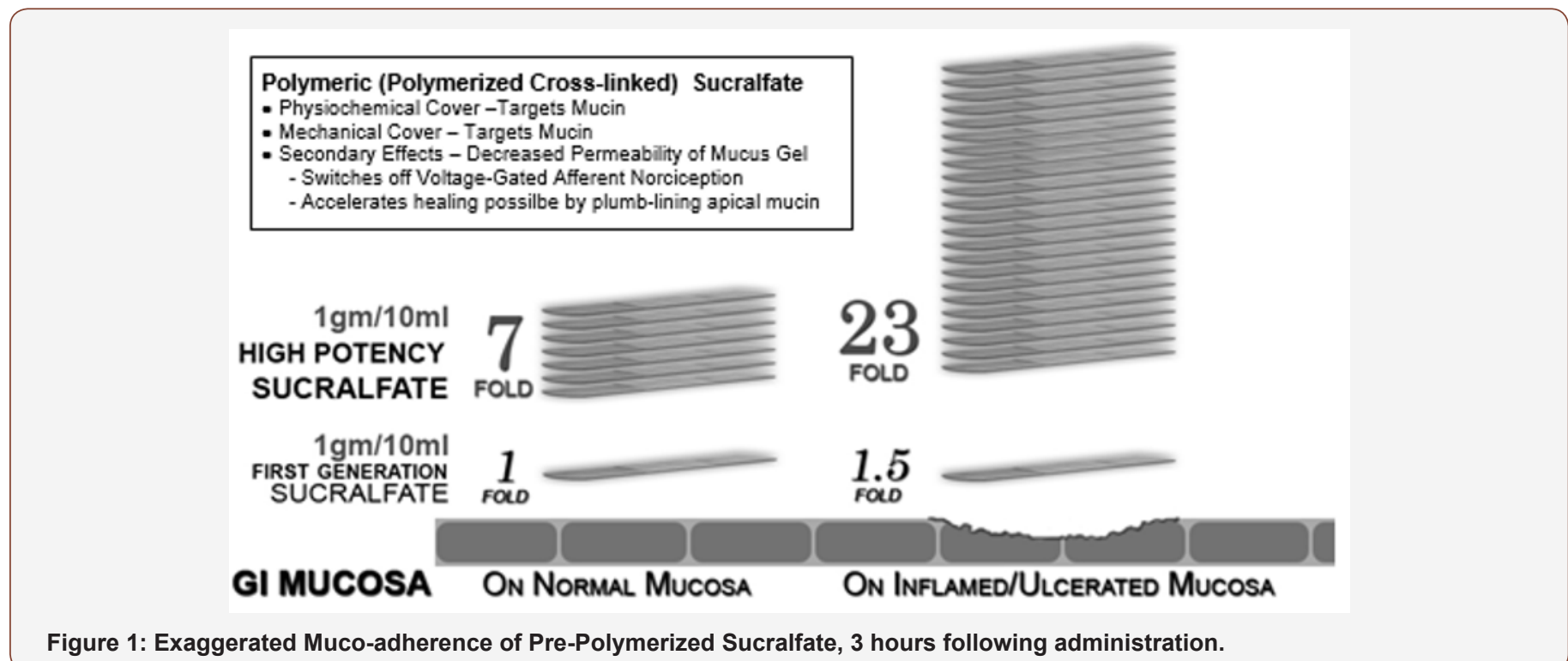

\section{Biological Basis of Sucralfate's Therapeutic Action}

Sucralfate is non-systemic cytoprotectant expelled from the colon in chemically unaltered amounts that are $95 \%$ to $98 \%$ of ingested dose [85]. Being a therapy that relies on coating the mucosal lining, the entirety of its clinical effect resides in the surface concentration of sucralfate that can be achieved and/or maintained. Polymerized sucralfate barrier therapy preferentially engages mucin, the biophysical cover of the enteric mucosa [86-88]. Neither denuded epithelium, its apical surface, nor growth factors located on its basolateral membrane provide areas of engagement for sucralfate. Because near immediate mucosal reactions occur (epithelial regeneration, mucus secretion, prostaglandin release etc) when large concentrations of dissolving sucralfate adhere to the mucosa, some researchers have asserted that clinical effects of sucralfate emanate from its molecular engagement of growth factors expressed on enteric epithelium [89]. However, epithelialassociated growth factors are located on basolateral surface beneath epithelial tight junctions and not near the apical surface of the epitheliium beneath the mucus gel and the lumen into which sucralfate is introduced and remains. Additionally, from 30 years of basic science research on sucralfate (from 1987 to 2017) in multiple investigations (in vitro, in vivo, with or without growth factors), no evidence has emerged to support sucralfate-growth factor interaction as the seminal event driving its cytoprotective actions. Instead there has been considerable evidence suggesting that no working relationship exist between luminal sucralfate and epithelial bound growth factors [90,91]. In fact, transmission electron micrographs, scanning electron micrographs and unfixed freeze-fractured, and freeze-dried electron micrographs demonstrate that sucralfate prefers mucin or fibrin for binding and that none adheres to or lies near apical epithelium of the GI tract, even over epithelium denuded of mucin or fibrin [86,87]. Clearly post-ingested sucralfate can be found bound to the mucin gel compartment in a manner of decreasing gradient from the outer to inner aspect of the mucin layer [88]. 
The biophysical nature of mucin's relationship with enteric epithelium holds the key for sucralfate's clinical effects. From the author's research, it seems that the structural reaction of mucin to the transient coating of sucralfate is parlayed into mucin-directed molecular effects within the mucosal lining. These mucin-directed molecular efffects culminate into cytoprotective clinical effects of sucralfate. Thus, it seems, that without the physical effects of a sucralfate coating on the biophysics of mucin, cytoprotective clinical effects of sucralfate simply would not occur.

\section{Early Experimental Observations of Mucosal Reac- tion to Sucralfate - Rapid \& Dramatic}

Running in parallel to approved clinical uses of sucralfate from 1982 through 1995, were translational medicine research on the physiologic basis of the clinical effects of sucralfate. Early observations, well chronicled by Hollander and Tygat [92], were dramatic and occurred rapidly. Immunologic understanding of the enteric mucosa was in its infancy at that time, so many of the histologic, ultrastructural and functional reactions of the mucosa to sucralfate while observed was not well understood. The mucosal events were as follows. First, as stated above, sucralfate targeted mucin and not bare epithelium. Its adherence seen by endoscopy was with mucin within the mucus gel [86-88]. Secondly, sucralfate's engagement with mucin strengthen the integrity of the gel and did so in a dose dependent fashion [93]. There was an immediate multifold enhancement of mucus viscosity, a $60 \%$ increase in its hydrophobicity which in turn caused decreased permeability of (a) hydrogen ions (acid) [94], (b) cations (e.g., calcium) [95], and (c) bile acids [96]. Sucralfate engagement of mucin inhibited endogenous proteases (pepsin, trypsin, and chymotrypsin) [97] and exogenous mucolytic proteases of Helicobacter pylori $[98,99]$.

Thirdly, endoscopic examination of partially dissolved, partly polymerized sucralfate tablets resting on the greater curvature of the stomach, revealed near immediate histologic, ultrastructural, and functional changes occurring within the epithelium circumferientally around the partly dissolved, partly polymerized sucralfate fragments $[100,101]$. Specifically from 5 to 60 minutes, sucralfate's non-chemical electrostatic physical engagement of mucin, led to increased mucin release, increased luminal release of prostaglandin E2 and signs of epithelial cell renewal generally centered at the physical site of contact with partially polymerized but firmly adherent sucralfate tablet [100]. At that time, in 198688, the importance of sucralfate's engagement of mucin was not connected to these mucosal events, because the physiology of mucin was not that well understood and its biophysically connected humoral relationship with the enterocyte was not broadly studied. So the connections and insights provided in this review could not have been made at that time. The science of the mucosal barrier its role in biophysical modulation of intra-cellular epithelial processes was simply not that well understood then. But what was clear, now in hindsight, is that the reasons for rapid and dramatic changes observed at the time was that doses used in experimental animals were 5-10 fold the usually $14 \mathrm{mg}$ per kg dose permitted in clinical practice. Even the in vivo observations in human subjects involved partially dissolved, polymerized fragments of sucralfate tablets which in essence, for the small 5 square centimeter area of the human stomach replicated the multifold dosages given to experimental animals. What Tarnawski et al [100] saw in humans endoscopically were the effect on 5-10 cm concentric area of stomach hosting in its center a 1 gram half dissolved tablet of polymerized sucralfate sitting on the stomach's greater curvature. The dose of sucralfate received by mucin overlying that $5-10 \mathrm{~cm}$ concentric area was far greater than the $14 \mathrm{mg}$ per $\mathrm{kg}$ dose for an entire $70 \mathrm{~kg}$ patient.

In 1987 the reasons those observations occurred were unclear, largely because the physiological link between mucin and the underlying epithelium had not been elucidated. To understand how pre-polymerized sucralfate can be effective in NERD and how it can be causally associate with $80 \%$ complete healing of eGERD in 7 days it is necessary to review current knowledge of enteric mucosal barrier.

\section{The Enteric Mucosal Barrier coated by Polymerized Sucralfate}

In 1987, investigators did not have the advantage of 30 years of research that has transpired in understanding the physiology of the enteric mucosal barrier. A brief overview of the mucosal barrier will aid understanding of how dose-dependent sucralfafe coatings are parlayed into clinical effects reported for polymerized sucralfate in the treatment of erosive GERD and NERD.

As shown in Table 2, there are three histological compartments of the mucosal barrier and they include the mucin (mucus gel) compartment, the single-cell epithelial compartment and the subepithelial compartment or lamina propria [102].

For perspective, the single-cell epithelial layer has associated lower layers of basal epithelial stem cells riding above the lamina propria within which the basolateral surface of the enterocyte (situated below the epithelial tight junctions) participates as a functional member of the submucosal lamina propria. Submucosal immune cells (mast cells, monocytes, macrophages, neutrophils, basophils, B- and T-lymphocytes), neuro-fibers specialized with nociceptors and capillaries lined with malleable endothelium. The single-cell epithelium is 20 microns, its apical transmembrane mucin of the glycocalyx is 0.5 to 1.5 microns, above which is an adherent layer of mucus (absent in distal esophagus [103]) of 30 microns. Above the 30 micron adherent layer of mucus is a 200 450 micron layer of loosely adherent mucus layer, which in the esophagus is supplied by the salivary gland secretions, submucosal goblet cells and apical epithelial membrane.

While somewhat beyond the main focus of this report, it is worth mentioning that there are at least seven barrier functions conducted across three histological compartments as shown in the Table 2. Listing these functions provide perspective to the meaning of cytoprotective homeostasis provided by the coating of polymerized sucralfate. Continuous homeostatic functions of the mucosal lining include (1) functions to cover, capture, deflect then remove luminal assailants and (2) functions to neutralize luminal 
offenders and preserve physical epithelial structure covering the submucosa, group functions overseen by the mucus gel. Then (3) functions of antigen and non-antigen surveillance, detection, barrier lubrication and sustenance and (4) functions to cap and close out luminal contents using tight cell to cell attachment proteins, which are group functions overseen by the single cell epithelium. Then lastly there are the (5) pre-emptive immune activity by innate immune cells, the (6) counterattack pro-inflammatory actions of the adaptive immune cells and (7) the functions that warn host through the enteric nervous system, secretory chemosensor cells that can initiate rapid (cathartic) elimination of offending luminal contents, all which are the third group of barrier functions exclusive to the lamina propria (Table 2).

Table 2: Structural Biology and Function of a Healthy Mucosal Barrier.

\begin{tabular}{|c|c|c|c|}
\hline Barrier Compartments & & Barrier Functions & Functional \& Cellular Elements \\
\hline \multirow[b]{2}{*}{ Mucins } & 1 & Cover, Capture, Deflect, Remove & $\begin{array}{c}\text { Loose Mucin labyrinth, sterile dense Adherent Mucin, Mucin } \\
\text { Transient }\end{array}$ \\
\hline & 2 & Neutralize and Preserve & $\begin{array}{l}\text { Neutralize using IgA, anti-microbial agents, detached } \\
\text { transmembrane mucin; Preserve epithelium using trefoil factors } \\
\text { (TFF1, TFF2, TFF3) }\end{array}$ \\
\hline \multirow[t]{2}{*}{ Single Cell Epithelium } & 3 & $\begin{array}{l}\text { Antigen \& non-antigen Surveillance, } \\
\text { Detection, Barrier lubrication \& } \\
\text { Sustenance }\end{array}$ & $\begin{array}{l}\text { Sample surveillance by } \alpha \beta \text {-IEL, } \delta \gamma \text {-IEL, M-cells, dendritic } \\
\text { cells, goblet cells; detect mucin disturbance by epithelial } \\
\text { transmembrane mucin; lubricate and sustain epithelium by } \\
\text { Globlet cells producing mucin, trefoil factors; tuft cells and } \\
\text { enteroendocrine cells. }\end{array}$ \\
\hline & 4 & Cap and Close off Luminal Contents & $\begin{array}{l}\text { Epithelial Cells with toll-like receptors, tight junctions, epithelial } \\
\text { cytokine production, apical transmembrane mucin \& cytosol } \\
\text { signaling, basolateral growth factors }\end{array}$ \\
\hline \multirow[b]{3}{*}{$\begin{array}{l}\text { Lamina Propria and Submucosa to } \\
\text { Subserosa }\end{array}$} & 5 & Pre-emptive Immune Actions & $\begin{array}{l}\text { Innate Immune Cells (ILC)- Class I, II, III interacting with } \\
\text { epithelial cells, IEL's, Globlet cells, Dendritic cells, M-Cells }\end{array}$ \\
\hline & 6 & $\begin{array}{l}\text { Adaptive Counter-Attack Immune } \\
\text { Actions }\end{array}$ & $\begin{array}{l}\text { Monocytes, Macrophages, Mast Cells, B- Lymphocytes, } \\
\text { T-Lymphocytes, inflammasome formation }\end{array}$ \\
\hline & 7 & $\begin{array}{l}\text { Host Warning and Eliminate } \\
\text { Effluent }\end{array}$ & $\begin{array}{l}\text { Enteric glial neurons with } 2 \text { classes of voltage-gated receptors } \\
\text { (ASIC, TRPV) on afferent neurons, with input to efferent neurons } \\
\text { that are responsive to cytokine secretions from IEL, epithelial } \\
\text { cells, mast cells and ILC's; these neurons extend from the } \\
\text { epithelial cell layer (including tuft cells and enteroendocrine cells) } \\
\text { downward into the submucosal plexus and myenteric plexus, with } \\
\text { functions for sensory, epithelial, vascular, pain, nausea, emesis } \\
\text { and motility. }\end{array}$ \\
\hline
\end{tabular}

These seven barrier functions distributed across three histological compartments are covered by the mucin gel which requires the biophysical stability, generally provided by luminal coating of sucralfate. Mucosal homeostasis is served seamlessly by these seven barrier functions, which in turn are all preserved by the biophysical integrity of overlying mucin. Irritants of gastric refluxate penetrating the mucin gel are detected by nociceptors of afferent submucosal neurons and incite inflammatory reactions that are in turn registered as pain (dyspepsia, heartburn etc,) These inflammatory reactions can also affect normal epithelial differentiation in the esophagus. Thus the integrity of the mucin gel compartment is physically linked to the health of the epithelial and subepithelial layer of the esophagus. It is also the targeted site of engagement for pre-polymerized sucralfate.

\section{Biophysical Integrity of the Mucin Gel Reinforced by Sucralfate}

The mucin compartment, targeted by sucralfate, is comprised of two distinct mucus layers that have a rapid turnover. It is estimated that the mucus gel is replaced at least 17.8 times per 24 hours, being calculated from the rate of mucus turnover in the rat [104-106] comparatively correlating it to the entire human GI tract [107]. Up A considerable volume of mucus is secreted into the GI tract daily [108]. Mucin are glycoproteins comprised of more than $80 \%$ carbohydrate [109], having a linear protein structure with covalently bonded branched glycans attached to the hydroxyl group of threonine and serine, giving mucin a bristled bottle-brush appearance. Distributed along the protein strand are cysteine-rich domains that permit intermolecular bonding to form dimeric and multimeric mucin. Multimeric mucin is then packed through hydrogen bonding into mucin networks with varying degrees of hydration. Containing large amounts of water coverts mucin networks into gels. The glycans in gel forming mucins resist breakdown by digestive enzymes and function to structurally protect and lubricate the oropharynx and GI tract. It is here where pre-polymerized sucralfate work to bring about its clinical effects.

Corporeal integrity of the esophageal mucosa rests with epithelial cells structurally fitted with apical calyxes of transmembrane mucins interwoven and fasten at cysteine rich 'midpoints of MUC2 mucin strands within the overlying adherent mucus gel [110]. Epithelially attached transmembrane mucins are interwoven largely into the adherent mucin gel and to a lesser extent into the loose layer of mucin. Trefoil factors derived from adjacent goblet cells are induced by neighboring epithelial cells that express transmembrane mucins. Multimeric complexation of trefoil 
factors with the glycocalyx acts as 'antennae stabilizers', significant alteration of which can trigger cytosol release of intracellular sections of transmembrane mucin. Detached intracellular sections of transmembrane mucin then participate in signaling pathways that modulate the transcription of pro-inflammatory and antiinflammatory effector molecules (e.g., NF-kB). The type, extent and quality of cytosol signaling will vary in accordance to the type of transmembrane mucin involved (MUC1, 3, 4, 12, 13, 16 or 17). Biophysical stabilization of mucin facilitate continuance of homeostatic processes, occurring both within the mucin compartment and most importantly in the underlying epithelial and lamina proprial compartments.

The second layer of mucin is less soluble adherent layer of mucin [110] generally devoid of bacteria [111]. This mesh work of adherent gel physically interwoven to distal ends of transmembrane mucin protects epithelial cells from harm while their proximal intracellular ends of transmembrane mucins are involved in intracellular pathways that regulate inflammation, differentiation, apoptosis, and cell-cell interactions [112].

Distributed within both soluble and adherent mucus layers are three families of trefoil factors, TFF1, TFF2 and TFF3 [113]. Trefoil peptides share a 40-amino-acid sequence shaped as a three-leaf clover of covalent loops (trefoil domain) stabilized through three internal disulfide bonds between six cysteine (nonessential) amino acids, rendering trefoils resistant to degradation by protease, acid, or heat. TFF1 and TFF3 contain a single trefoil domain, while TFF2 has two. But unlike TFF3, TFF1 and TFF3 have a free cysteine residue in their $\mathrm{C}$-terminal used to form covalent dimers with TFF peptides or other proteins (cysteine rich domains of mucins, which themselves aggregate in multimeric fashion).

Trefoil factors direct epithelial migration above the basement membrane of damaged or denuded epithelium [114,115]; it is a mucin-compartment process known as epithelial restitution. Trefoil factors are distributed along the epithelium within the adherent and soluble mucus gel. Trefoil-driven restitution is the first elemental step to restore barrier integrity and is generally completed within 10-30 minutes of injury [116]. Thus it can be imagined that concentrations of trefoil factor supplied to mucin layers by oral salivary glands and by epithelial and goblet cells of esophagus, stomach and colon are maintained at constitutive levels, so that, if needed, can be locally augmented through feedback control (e.g., cytosolic or nuclear pathways) to ramp up local production of trefoil factors.

In GERD, TFF3 expression is increased [117]. It is coexpressed from goblet cells with MUC 2 [118], known to bind von Willebrand factor C (VWFC) domains of adherent and loose mucins for oligomerization. The resultant trefoil-complexed mucin yields a mucus gel of high viscosity [119]. VWFC domains are on MUC4 a transmembrane mucin produced by epithelial cells, but in concentrations that are lower in eGERD compared to NERD and controls [120]. Therefore its expression is sensitive to the presence of or the mucosal effect of acidic protons. Normally MUC 4 elaborated by enterocyte for expression on its apical surface where it is associates with anti-adhesive properties of the enterocyte (creating a steric barrier for anti-body binding) and cytoprotection [121]. Because MUC 4 can be regulated transcriptionally (by multiple promoter sites via different transcription factors and signaling pathways), epigenetically (by DNA methylation or histone acetylation) and post-translationally by TGFß (through a proteosomal degradation) [121], it is likely a cytoprotective modulator activated by complexation with TFF3 or wildcard negative modulator. Polymerized sucralfate provide biophysical stability to these cytoprotective processes.

\section{Molecular Basis of the Clinical Effects of Polymerized Sucralfate in GERD}

The site of sucralfate engagement on the mucosa, is not the epithelium, but mucin within the mucus gel $[86,88]$. This is unambiguous. The means by which the transient engagement of sucralfate with mucin convert into cytoprotection is better understood today than during the 1980's research of Tarnaswki, et al. [100,101], Hollander, et al. [122, 123], Slomiany, et al. [93-99] and others [97, 124-127]. The biological basis of the therapeutic actions of sucralfate (its engagement of mucin) is the molecular basis for its clinical effects. In the 1980's it was confirmed that a dose-dependent engagement of sucralfate with mucin resulted in rapid ultrastructural, histological and functional reactions [100]. What is now understood, but at that time not well appreciated, were the structural nuances of the mucosal barrier, and particularly the structure-function relationship between secretory mucins, transmembrane mucins, trefoil factors [128],cytoprotective complexation of mucin [112] and the translation of mucin's biophysical signals into intracellular signaling pathways within the epithelial enterocyte [112,129]. Among the first molecular events of dose-dependent sucralfate-mucin engagement is (1) enhancement of mucin viscosity [94], (2) the increase of hydrophobicity [93] and (3) structural stiffening of mucus gel layer [93]. These physicochemical changes are dose-dependent consequences of sucralfate coating. These changes deny permeation of protonic acid across the mucus gel compartment, thus slowing activation of ASIC and TRPV1 nociceptors, to silence pain. Enhanced hydrophobicity limits access of bile acids to cross the mucus gel compartment [42,96] which both disallows activation ASIC and TRPV1 nociceptors and prohibits incitement of cytokine-mediated inflammation $[29,47,48]$. The electronegativity of sucralfate's dose-dependent engagement of mucin creates steric hindrance to proteases [97,99] disallowing activation of PAR-2 receptors in the epithelium [130]. Sucralfate engaged mucin is also an electrostatic impediment to cations (calcium, sodium, and potassium) slowing their passage across mucus gel which is generally more hydrophilic due to its water content [95]. Biomechanical stiffening of the mucin gel may provide structural transmission of biophysical signals to apical epithelium and goblet cells [129-131] by way of transmembrane mucins that stud their apical surface, triggering the cytoprotective 
secretion of trefoil, prostaglandin E, additional hydrophobic mucin, and bicarbonate $[100,101,123]$. By blockade of caustic acid, bile acids, serine protease and cations, the dose-dependent sucralfatemucin engagement facilitate diminution of afferent firing of nociceptors (pain/discomfort relief), defervesce of cytokine-driven inflammation and reversion to normal mucosa, the healing process.

\section{Synopsis of Randomized Controlled Trials}

The five physical effects of a dose-dependent sucralfatemucin engagement should issue in clinical effects on erosive GERD and NERD from pre-polymerized sucralfate that are not observed using standard sucralfate, because, as shown in Figure 1 , at 3 hours post-administration, PPSBT achieves and maintains surface concentrations of sucralfate that are 7 to 23 times that of standard sucralfate. These elevated surface concentrations, i.e., enhanced potency, should parlay all five physical effects into positive clinical outcomes. In the three randomized controlled trials [11] unexpected clinical outcomes did occur. In a word, the investigations demonstrated that in 7 days low daily doses of prepolymerized sucralfate ( 3 grams daily) were better than placebo in the healing of erosive GERD when compared to omeprazole (40mg daily), ranitidine (300mg daily) and better than placebo in 28 days. Over 28 days, for patients with undifferentiated NERD, 3gam of pre-polymerized sucralfate provided symptomatic relief better than placebo. Undifferentiated NERD is a cohort of non-erosive GERD patients who have functional heartburn, esophageal reflux hypersensitivity and classic NERD in undetermined proportions.
In general, $50 \%$ of undifferentiated NERD have classic NERD, while $30 \%$ have functional heartburn, and $20 \%$ have esophageal reflux hypersensitivity [132]

\section{PPSBT in Erosive GERD}

Each of the three trials were appropriately powered and had statistically relevant sample sizes of patients entered into data analysis. Randomized participants of treatment groups were evenly represented in terms of gender, age, years of symptoms, presence of helicobacter and hiatal hernia. Participant attrition (those lost to follow up) was minimal, less than $12 \%$ on average and patient compliance with trial regimens was high [133]. Therefore, reported outcomes were relevant under the controlled settings of trials. A daily total symptom score, comprised of number, type and severity of symptoms quantified by Likert Scale of 0 to 4 was used to compare pre-trial and post-trial scores. Heartburn, reflux sensation and retrosternal chest pain were among the symptoms evaluated. Healing was assessed by Hetzel-Dent grading system [134]. Complete healing occurred when there was endoscopic absence of erosions immediately following trial, that is a Hetzel-Dent Grade 0 or 1 . Partial healing was improvement by at least 1 Grade but still above Hetzel-Dent Grade 1. No healing was noted when there was complete endoscopic absence of improvement in grade of erosions. Specific outcomes listed in Table 3 report symptomatic relief and healing from PPSBT over 28 days compared to placebo and from PPSBT over 7 days compared to omeprazole, ranitidine, and antacids.

Table 3: Comparative Relief of Heartburn in Erosive GERD in 7 days and 28 days.

\begin{tabular}{|c|c|c|c|c|c|c|}
\hline Intervention & 7 day Antacids & 7 day Ranitidine & 7 day Omeprazole & 7 day PPSBT & 28 day PPSBT & 28 day Placebo \\
\hline Non-Responders & $20 \%(\mathrm{n}=2 / 10)$ & $34 \%(\mathrm{n}=2 / 9)$ & $10 \%(\mathrm{n}=1 / 10)$ & $20 \%(\mathrm{n}=2 / 10)$ & $11.1 \%(\mathrm{n}=1 / 9)$ & $75 \%(\mathrm{n}=6 / 8)$ \\
\hline Responders & $80 \%(\mathrm{n}=8 / 10)$ & $66 \%(\mathrm{n}=7 / 9)$ & $90 \%(\mathrm{n}=9 / 10)$ & $80 \%(\mathrm{n}=8 / 10)$ & $88.9 \%(\mathrm{n}=8 / 9)$ & $25 \%(\mathrm{n}=2 / 8)$ \\
\hline \multicolumn{2}{|r|}{ Omperazole 20mg bid; Ranitidine $150 \mathrm{mg}$ bid; Antacids $30 \mathrm{ml}$ qid $(400 \mathrm{mgAlOH} 2 / 400 \mathrm{mgMgOH} 2 / 10 \mathrm{ml}) ;$ PPSBT $1.5 \mathrm{gram}$ bid } \\
\hline
\end{tabular}

In 28 days, PPSBT reduced symptoms of heartburn and reflux sensation in $89 \%$ of participants compared to those using placebo (19\%). This is the first time any sucralfate therapy was associated with this degree of efficacy in trials performed in manner consistent with Cochran standard of minimal bias $[135,136]$. Similar symptomatic outcome was noted using PPSBT for 7 days. Figure 2 shows that symptomatic relief with PPSBT in 7 days (80\%) was comparable to that observed in eGERD patients on omeprazole (90\%), ranitidine (66\%) and antacids (80\%).

Figure 2 also illustrates an interesting observation that, in 7 days, symptomatic relief from PPSBT (80\%) is nearly 90\% of symptomatic relief achieved by PPSBT in 28 days of PPSBT (88.9\%). In other words the mechanisms used by PPSBT to achieve symptomatic relief seem to be established early, that is within the first 7 days of therapy. Table 4 shows endoscopic healing using the five interventions, placebo, antacids, ranitidine, omeprazole and PPSBT. Over 28 days healing of erosive GERD in patient using placebo was $19 \%$. Within 7 days, despite relatively high symptomatic relief, healing of eGERD in patients using antacids (0\%), ranitidine (0\%) and omeprazole (30\%) was low, while healing in patients using PPSBT was high (80\%). Again, it is observed that the mechanism underlying healing with PPSBT is likely substantially operative with 7 days, given that over $90 \%$ of healing achieved by 28 days using PPSBT occurs within the first 7 days.

Figure 3 illustrates the extent of endoscopic healing in erosive GERD using all five interventions. 


\section{PERCENT COMPARATIVE HEARTBURN RELIEF EROSIVE GERD IN 7 DAY \& 28 DAYS}

- Responders = Non-Responders
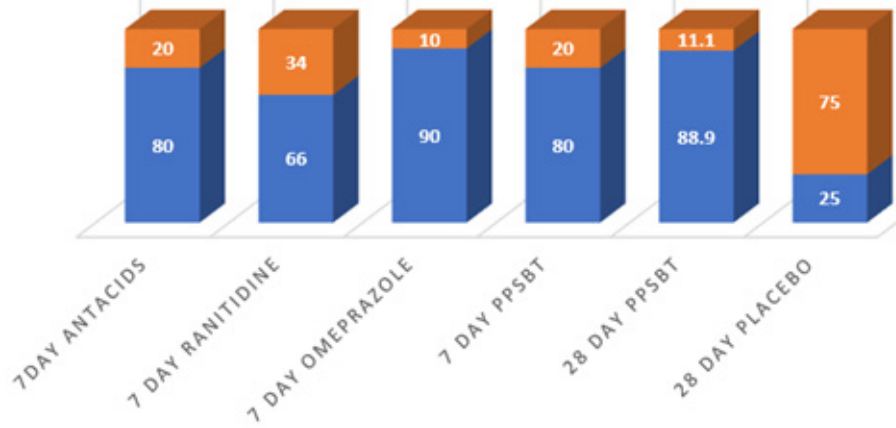

Figure 2: Percent comparative relief of heartburn in 7 days and 28 days.

All interventions except placebo were associated with heartburn relief that was largely comparable.

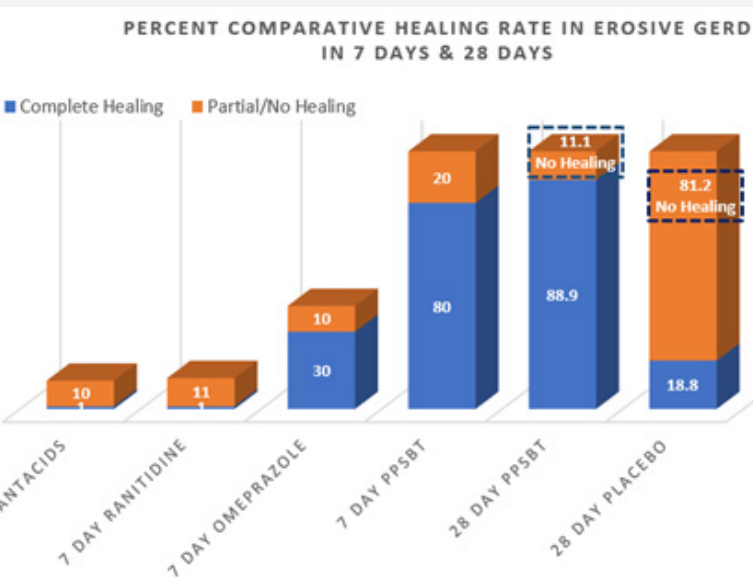

Figure 3: Percent comparative healing rate of erosive GERD in 7 days $\& 28$ days.

In 7 days only PPSBT associated with substantial healing. After 28 days PPSBT healing rate improved some. However nearly $90 \%$ of healing rate to be achieved by PPSBT occurred within the first 7 days.

Table 4: Comparative Healing of Erosive GERD in 7 days and 28 days.

\begin{tabular}{|c|c|c|c|c|c|c|}
\hline Intervention & 7 day Antacids & 7 day Ranitidine & 7 day Omeprazole & 7 day PPSBT & 28 day PPSBT & 28 day Placebo \\
\hline Partial Healing & $10 \%(\mathrm{n}=1 / 10)$ & $11 \%(\mathrm{n}=1 / 9)$ & $10 \%(\mathrm{n}=1 / 10)$ & $20 \%(\mathrm{n}=2 / 10)$ & $* * 11.1 \%(\mathrm{n}=1 / 9)$ & $* * 81.2 \%(\mathrm{n}=6 / 8)$ \\
\hline Complete Healing & $0 \%(\mathrm{n}=0 / 10)$ & $0 \%(\mathrm{n}=0 / 9)$ & $30 \%(\mathrm{n}=3 / 10)$ & $80 \%(\mathrm{n}=8 / 10)$ & $88.9 \%(\mathrm{n}=8 / 9)$ & $18.8 \%(\mathrm{n}=2 / 8)$ \\
\hline
\end{tabular}

Table 5: Ratio of Healing to Relief in Erosive GERD in 7 days and 28 days.

\begin{tabular}{|c|c|c|c|c|c|}
\hline Intervention & 7 day Antacids & 7 day Ranitidine & 7 day Omeprazole & 7 day PPSBT & 28 day PPSBT \\
\hline Overall Healing & $10 \%(\mathrm{n}=1 / 10)$ & $11 \%(\mathrm{n}=1 / 9)$ & $40 \%(\mathrm{n}=4 / 10)$ & $100 \%(\mathrm{n}=10 / 10)$ & $88.9 \%(\mathrm{n}=8 / 9)$ \\
\hline Overall Relief & $80 \%(\mathrm{n}=8 / 10)$ & $66 \%(\mathrm{n}=7 / 9)$ & $90 \%(\mathrm{n}=9 / 10)$ & $80 \%(\mathrm{n}=8 / 10)$ & $88.9 \%(\mathrm{n}=8 / 9)$ \\
\hline Ratio H/R & 0.125 & 0.167 & 0.444 & 1.25 & 1 \\
\hline \multicolumn{2}{|r}{ Omperazole 20mg bid; Ranitidine 150mg bid; Antacids 30ml qid (400mgAlOH2/400mgMgOH2/10ml); PPSBT 1.5gram bid } \\
\hline
\end{tabular}

In Table 5 it can be seen that 7 day symptomatic relief from antacids, ranitidine and omeprazole is incongruent with healing by these intervention over the same period of time. Examining healingas a function of relief, Figure 4 illustrates a near 1 to 1 ratio of high symptomatic relief to high degree of healing in patients using PPSBT in 7 days; the opposite is observed for antacids, ranitidine, and omeprazole. In patients taking antacids, ranitidine and omeprazole, the proportion of those receiving relief without substantial healing was high. This implies that, contrary to clinical guidelines $[1,3,4]$, interventions whose sole mechanism of action 
centered on elevating $\mathrm{pH}$ is not sufficient to reverse mucosal inflammation within 7 days. This data support points made earlier that caustic acid alone may not be the sole cause of the mucosal reaction to reflux. As stated, from these trials as well as from the literature [36,50,51,137]. bile acids and serine proteases (trypsin, chymotrypsin) are co-equal irritants in gastric refluxate.

PPSBT does not alter gastric pH. It coats the mucus gel, biophysically altering its properties to minimize access of acid to neurofibers with nociceptors that can be switched on by protonic ions. Symptomatic relief from PPSBT within the first 7 days suggests that limiting biophysical access of acid to the mucosa is a legitimate mechanism of action. Also obvious (from Figurers $3 \& 4$ ) is that the relative absence of mucosal healing in the setting of substantial relief early on (the first 7 days) that acid-controlling therapies may require supplementary interventions to address non-acid irritants of esophageal mucosa. The incidence of substantial healing in the setting of significant relief in patients using PPSBT during the first 7 days suggests PPSBT use may supplement acid-controlling therapies, as there was only $30 \%$ healing with omeprazole in 7 days. There has been a reported anti-inflammatory effect of PPI's in patients with GERD $[46,138]$. Clearly, in this trial, any direct antiinflammatory effect of omeprazole was 2.6 fold less effective than that observed with PPSBT, an effect achieved solely by the ability of PPSBT to physically deny irritants access to the esophageal mucosa.

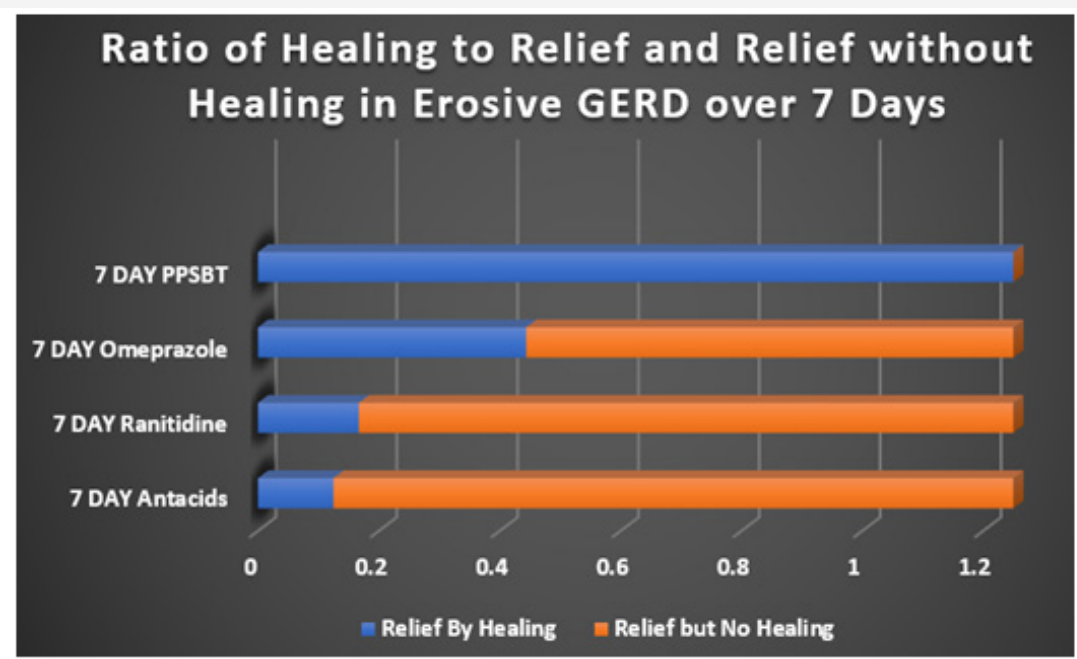

Figure 4: Ratio of Healing to Heartburn Relief in 7 days.

The ratio of overall healing to overall relief in patients with erosive GERD taking omperazole $20 \mathrm{mg}$ bid, ranitidine $150 \mathrm{mg}$ bid, antacids $30 \mathrm{ml}$ qid (400mgAlOH2/400mgMgOH2/10ml) and PPSBT 1.5gram bid over 7 days. The healing/relief ratios from interventions were normalized to the healing/relief ratio observed with 7 day PPBST to approximate the proportion of those having relief without healing.

\section{PPSBT in NERD}

There are no specific management guidelines for NERD. The Vevey NERD Consensus Group, excludes functional heartburn and reflux hypersensity from the NERD patient cohort and recommend use of acid-controlling therapies, PPI's, H2RA and antacids where useful [139]. However, clearly the similarity of histomorphology, transmembrane resistance, and immunoreactions in sub-cohorts of NERD patients excluded by Vevey [22-24] suggest that esophageal exposure to gastric refluxate has a decisive role in symptoms regardless of sub-type of NERD present. Thus, for all sub-types of NERD, physical exclusion of refluxate (or of dissolved irritants) is key. These patients too, are vulnerable to any one of the irritants in gastric refluxate.

As shown in Table 6, for patients with NERD, PPSBT was found to be more effective than placebo against three types of symptoms - heartburn, reflux sensation and retrosternal discomfort or pain.

Table 6: Symptomatic Outcome in Undifferentiated NERD in 28 Days.

\begin{tabular}{|c|c|c|c|c|c|c|}
\hline \multirow{2}{*}{$\begin{array}{c}\text { Intervention } \\
\text { NERD Symptoms }\end{array}$} & \multicolumn{3}{|c|}{ PPSBT } & \multicolumn{3}{|c|}{ Placebo } \\
\hline & Heartburn & Reflux & Pain & Heartburn & Reflux & Pain \\
\hline \% Responsive & $90 \%(n=18 / 20)$ & $83.3 \%(n=15 / 18)$ & $88.2 \%(n=15 / 17)$ & $11.1 \%(\mathrm{n}=2 / 18)$ & $25 \%(n=4 / 16)$ & $20 \%(n=3 / 15)$ \\
\hline$\%$ Non-responsive & $10 \%(n=18 / 20)$ & $16.7 \%(n=3 / 18)$ & $11.8 \%(n=2 / 17)$ & $88.9 \%(n=16 / 18)$ & $75 \%(n=12 / 16)$ & $80 \%(n=12 / 15)$ \\
\hline
\end{tabular}

Figure 5 illustrates the data listed in Table 6. Over 28 days, 90\% with heartburn, $83 \%$ with reflux sensation nf $88 \%$ with retrosternal discomfort responded to PPSBT, while the opposite was true for those using placebo.
Table 7 shows the composite of overall responders and nonresponders. There was minimal use of antacids in NERD patients using PPSBT. However, as seen in Figure 6, for NERD patients on placebo, antacid use was 6 fold greater. 


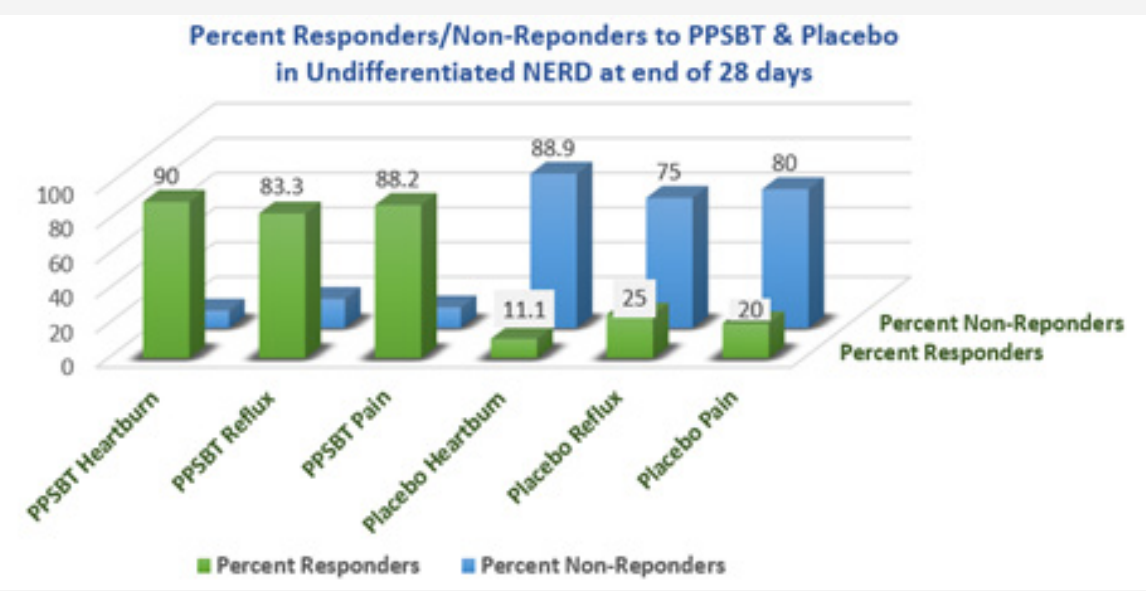

Figure 5: Percent responsive \& non-responsive in undifferentiated NERD GERD in 28 days.

In this cohort of undifferentiated NERD patients (containing functional heartburn, esophageal hypersensitivity, and classic NERD), PPSBT was associated with relief of heartburn, reflux sensation and retrosternal pain.

\section{Composite Symptom Response \& Antacid Use in Undifferentiated NERD over 28 days}

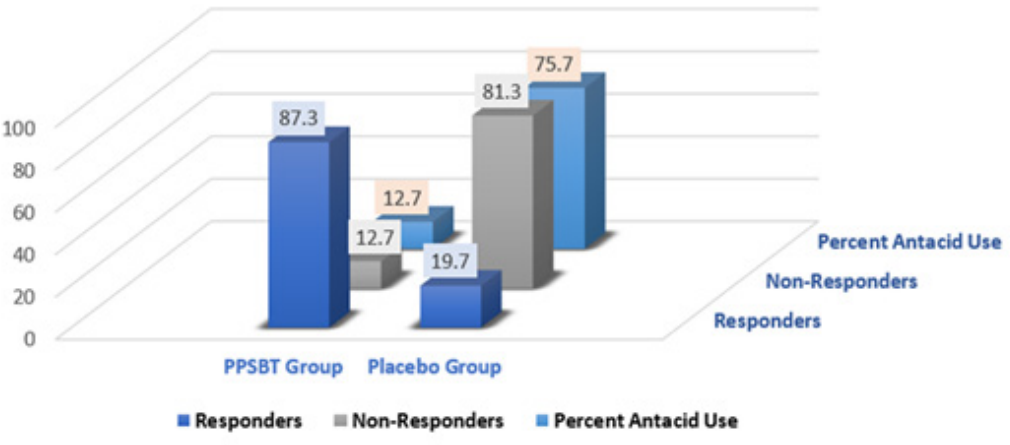

Figure 6: Composite Symptomatic response \& antacid use in undifferentiated NERD in 28 days.

In this cohort of undifferentiated NERD patients (functional heartburn, esophageal hypersensitivity, and classic NERD), PPSBT was associated with significant relief with minimal use of antacids.

Table 7: Composite Symptomatic Relief \& Antacid Use in Undifferentiated NERD over 28 Days.

\begin{tabular}{|c|c|c|c|}
\hline & Composite Responders & Composite Non-Responders & Percent Antacid Use \\
\hline PPSBT & $87.3(n=48$ of 55) & $12.7(n=7$ of 55) & $12.5(n=20$ of 160 btls $)$ \\
\hline Placebo & $18.4(n=9$ of 49$)$ & $81.6(n=40$ of 49$)$ & $75.7(n=109$ of 144 btls $)$ \\
\hline
\end{tabular}

PPSBT versus Other Sucralfate Preparations for eGERD and NERD

Patients with either erosive GERD or NERD appear to respond to PPSBT. Though early generations of sucralfate have been excluded from clinical guidelines for GERD [1, 2] and NERD [139] , there have been a handful of studies on sucralfate preparations for eGERD and NERD. Vermeijden, et al. [8] was the only sucralfate study for eGERD that qualified for inclusion in a Cochrane metaanalysis report and could be compared to PPSBT for efficacy in healing [136]. Comparing data on symptomatic control of eGERD was somewhat challenging due to difference in methodology to quantify symptomatic effect. However, the presence or absence of endoscopic erosions are more easily compared. Vermeijden, et al.
[8] observed that in 56 days, 4 grams daily of standard sucralfate (polymerized by gastric acid) achieved a healing rate of $68 \%$. Comparatively, PPSBT required 7 days using 3 grams daily to achieve $80 \%$ complete healing in patients with erosive GERD. While 56 days, 224 grams of sucralfate was used to achieve $68 \%$ healing; only 7 days, 21 grams of PPSBT was used to achieve healing of $80 \%$ for erosive GERD. In terms of days and dosage of sucralfate, PPSBT required $1 / 8$ the time and $10 \%$ of the dose to achieve healing rate that was better than that reported by Vermeijden, et al. [8].

In another study, Simon et al [5] used a 'gel' formulation of sucralfate to treat NERD patients and found it to be effective. Since the method used by Simon et al to assess relief differed from that used in PPSBT trials, a valid comparison for symptomatic relief using sucralfate gel was not possible with symptomatic relief using 
PPSBT. Still it could be said that 'gel' sucralfate required 42 days to achieve $71 \%$ symptomatic relief in NERD patient using 2 grams of sucralfate daily. In contrast to this, PPSBT required 28 days for $87 \%$ of NERD patients to have symptomatic relief using 3 grams of sucralfate daily. Whether it would have taken less time with PPSBT is unknowable since a 7 day, 14 day or 21 day outcome assessment was not performed.

\section{Conclusion}

Whether there is a role for PPBST in the management of GERD and NERD will likely be answered over a period of time. From previously reported data [11] reviewed here there appears to be some utility. Clearly from the literature discussed in this review, it appears that the loss of mucosal integrity is the determinative pathology in GERD and NERD and that effective therapeutic interventions that address mucosal integrity would be a welcomed option. Gastric acid permeation from the lumen to the esophageal epithelium is a widely accepted mode of pathogenesis for GERD and NERD $[43,139]$. Less known but clearly affirmed is the involvement of water soluble bile acids and serine proteases that cause mucosal reactions [36,38,41,49,51] which some believe if left unchecked proceeds to Barrett's esophagus [140] and to esophageal adenocarcinoma $[141,142]$.

All three irritants - acid, bile acids and proteases - give rise to cytokine-driven inflammatory changes within the esophageal mucosa $[29,143,144]$. Obviously, by mechanism of action, acid controlling therapies alone are an inadequate response for the clinical challenge.

The existential deterrent to mucosal injury by gastric refluxate is the biophysical integrity of the mucus gel. Dose-dependent engagement of pre-polymerized sucralfate with mucin [86-88] physically fortifies structural characteristics of the mucus gel, a fortification that results in at least five specific effects. The first effect is reduction of acid permeation through the mucus gel [94]; a second effect is hindrance of water-soluble bile acids to infiltrate mucus gel by sucralfate-associated enhancement of mucin hydrophobicity $[93,96]$; a third effect is the resilience of sucralfate-fortified mucin against degradation by serine proteases thus disallowing access to apical epithelium $[97,99,145]$ to perpetuate inflammation throughout squamous epithelium. A fourth effect is reduction of cationic penetration through the mucus gel [95] thereby starving the ion flux required to keep voltage-gated nociceptors switched on; the result of which is afferent neurofibres are switched off and dyspeptic discomforts are eliminated. The fifth specific effect is the least understood, but perhaps the most important. It involves sucralfate enhanced mucus gel viscosity [93] that is biophysically translated into intra-cellular signaling. It is the author's view that transduction of biophysicial 'stoutness' to intracellular signalaing is responsible for all near immediate ultrastructural, histological and humoral tissue changes, observed in the early days by Tarnawski, et al. [100,101]. Dose-dependent biophysical corpulence of sucralfate-engaged mucin result in an increased secretion of mucin, enhanced luminal expression of prostaglandin E2 and bicarbonate and simultaneous regenerative changes in the epithelium nearest the area of greatest sucralfate-mucin engagement.

The transduction of biophysical 'stoutness' into intracellular signaling is likely through agency of transmembrane mucins [112] which stud the apical surface of the epithelium and is interwoven with secretory mucin that is re-inforced by trefoil factors. Biophysical transduction of enhanced mucin gel integrity leads to anti-inflammatory and cytoprotective actions of epithelial cells accessorized by apical transmembrane mucin. This transduction of sucralfate-enhanced mucin biophysics is likely aided by complexation of globet-drived trefoil factors with the von Wildebrand factor segment of the transmembrane mucin [117]. Optimized trefoil complexation with transmembrane mucin modulates intracellular signaling that controls apoptosis, cell differentiation and pro-inflammatory and anti-inflammatory processes within the epithelial cell. Cytosolic segments of transmembrane mucin are known to translocate from the apical epithelial membrane to the nucleus [112] to participate in control of cytoprotective functions. This fifth effect of sucralfate-mucin engagement may be considered a viscosity associated optimization of a trefoil reinforced mucin-transmembrane mucin cross-linkage, a dose-dependent sucralfate-driven optimization that translates into intra-cellular signaling to drive reversal of pro-inflammatory mucosal damage $[113,114]$. These five effects likely explain the efficacy of pre-polymerized sucralfate in erosive and non-erosive GERD, for which a mechanism-of-action role in clinical practice guidelines seems apparent. High-potency sucralfate-mucin interactions, facilitated by transient hydrogen-bonding, may provide biologically meaningful cytoprotection in patients with erosive GERD and NERD.

\section{Acknowledgement}

None.

\section{Conflict of Interest}

Author is an employee of the company that owns a technology which polymerizes sucralfate.

\section{References}

1. Katz PO, Gerson LB, Vela MF (2013) Guidelines for the diagnosis and management of gastroesophageal reflux disease. Am J Gastroenterol 108: 308-328.

2. Huerta-Iga F, Bielsa-Fernández MV, Remes-Troche JM, Valdovinos-Díaz MA, Tamayo-de la Cuesta JL, et al. (2016) Revista de Gastroenterol Mex 81(4): 208-222.

3. Fock KM, Talley N, Goh KL, Sugano K, Katelaris P, et al. (2008) Asia-Pacific concensus on the management of gastroesophageal reflux disease: update. J Gastroenterol Hepatol 23: 8-22.

4. Armstrong D, Marshall JK, Chiba N, Enns R, Fallone CA, et al. (2005) Canadian Consensus Conference on the management of gastroesophageal reflux disease in adults -update 2004. Can J Gastroenterol 19: 15-35.

5. Simon B, Ravelli GP, Goffin H (1996) Sucralfate gel versus placebo in patients with non-erosive gastro-oesophageal reflux disease. Aliment Pharmacol Ther 10: 441-446. 
6. Hardy JG, Hooper G, Ravelli GP, Steed KP, Wilding IR (1993) A comparison of the gastric retention of a sucralfate gel and a sucralfate suspension. Eur J Pharmacol Biopharmacol 39(2): 70-74.

7. Vaira D, Corbelli C, Brunetti G, Menegatti M, Levorato $M$, et al. (1993) Gastric retention of sucralfate gel and suspension in upper gastrointerstinal diseases. Aliment Pharmacol Ther 7: 531-535.

8. Vermeijden JR, Tytgat GN, Schotborgh RH, Dekker W, vd Boomgaard DM, et al. (1992) Combination therapy of sucralfate and ranitidine, compared with sucralfate monotherapy, in patients with peptic reflux esophagitis. Scand J Gastroenterol 27(2): 81-84.

9. Nagashima R (1981) Development and characteristics of sucralfate. J Clin Gastroenterol 3(Suppl2): 103-110.

10. Oshea S (2019) Office of Combination Products. Request for Designation Sucralfate $\mathrm{HCl}$ Topical Paste.

11. McCullough RW (2014) Mucosa-Centric Clinical Effects of High Potency Sucralfate: 28 Day 83\% Resolution of Undifferentiated Dyspepsia, 28 Day 83\% Reversal of Sign \& Symptoms of Co-Morbid IBS and 1 Week $80 \%$ Healing of GERD. Gastroenterol 146(5 Suppl 1): S-263.

12. Bennett JR (2019) What is physiological gastroesophageal reflux.

13. Dent J, Dodds WJ, Hogan WJ, Toouli J (1988) Factors that influence induction of gastroesophageal reflux in normal human subjects. Dig Dis Sci 33(3): 270-275.

14. Dent J, Dodds WJ, Friedman RH (1980) Mechanism of gastroesophageal reflux in recumbent asymptomatic human subjects. J Clin Invest 65(2): 256-267.

15. Dodds WJ, Dent J, Hogan WJ, Helm JF, Hauser R, et al. (1982) Mechanisms of gastroesophageal reflux in patients with reflux esophagitis. NEJM 307: $1547-1552$

16. Drossman DA (2016) Functional gastrointestinal disorders: history, pathophysiology, clinical features and Rome IV. Gastroenterol 150(6): 1262-1279.

17. Aziz Q Fass R, Gyawali CP (2016) Esophageal disorders. Gastroenterol 150(6): 1368-1379.

18. Yamasaki T, Fass R (2017) Reflux hypersensitivity: a new functional esophageal disorder. J Neuorogastroenterol Motil 23(4): 495-503.

19. Woodland P, Al-Zinaty M, Yazaki E, Sifrim D (2013) In vivo evaluation of acid-induced changes in oesphageal mucosa integrity and sensitivity in non-erosive reflux disease. Gut 62: 1256-1261.

20. Farre R (2013) Pathophysiology of gastro-esphageal reflux disease: a role for mucosa integrity. Neurogastroenterol Motil 25: 783-799.

21. Weijenborg PW, Smout AJ, Verseijden C, van Veen HA, Verheij J, et al. (2014) Hypersensitivity to acid is associated with impaired esophageal mucosal integrity in patients with gastroesophageal reflux disease with and without espohagitis. Am J Physiol Gastrointest Liver Physiol 307: G323-G329.

22. Caviglia R, Ribolsi M, Maggiano N, Gabbrielli AM, Emerenziani S, et al (2005) Dilated intercellular spaces of esophageal epithelium in nonerosive reflux disease patient $\mathrm{s}$ with physiological esophageal acid exposure. Am J Gastroenterol 100: 543-548.

23. Kandulski A, Jechorek D, Caro C, Weigt J, Wex T, et al. (2013) Histomorphological differentiation of non-erosive reflux disease and functional heartburn in patients with PPI-refactory heartburn. Aliment Pharmacol Ther 38: 643-651.

24. Kanazawa Y, Isomoto H, Wen CY, Wang AP, Saenko VA, et al. (2003) Impact of endoscopically minimal involvement on IL-8 mRNA expression in esophageal mucosa of patients with non-erosive reflux disease. World J Gastroenterol 9(12): 2801-2804.

25. Fitzgerald RC, Onwuegbusi BA, Bajaj-Elliott M, Saeed IT, Burnham WR, et al. (2002) Diversity in the oesophageal phenotypic response to gastrooesophageal reflux: immunological determinants. Gut 50: 451-459.

26. Yu Y, Ding X, Wang Q Xie L, Hu W, et al. (2011) Alterations of mast cells in the esophageal mucosa of the patients with non-erosive reflux disease. Gastroenterol Res 4(2): 70-75.
27. Harnett KM, Rieder F, Behar J, Biancani P (2010) Viewpoints on acid-induce inflammatory mediators in esophageal mucosa. J Neurogastroenterol Motil 16(4): 374-388.

28. Isomoto H, Wang A, Mizuta Y, Akazawa Y, Ohba K, et al. (2003) Elevated levels of chemokines in esophageal mucosa of patients with reflux esophagitis. Am J Gastroenterol 98: 551-556.

29. Souza RF, Huo X, Mittal V, Schuler CM, Carmack SW, et al. (2009) Gastroesophageal reflux might cause esophagitis through a cytokinemediated mechanism rather than caustic acid injury. Gastroenterol 137(5): 1776-1784.

30. Farré R, van Malenstein H, De Vos R, Geboes K, Depoortere I, et al. (2008) Short exposure of oesophageal mucosa to bile acids, both in acidic and weakly acidic conditions, can impair mucosal integrity and provoke dilated intercellular spaces. Gut 57: 1366-1374.

31. Brock C, Gregersen H, Gyawali CP, Lottrup C, Furnari M, et al. (2016) The sensory system of the esophagus- what do we know. Ann NY Acad Sci 1380: 91-103.

32. van Hoeij FB, Weijenborg PW, van den Bergh Weerman MA, van den Wijngaard RM, Verheij J, et al. (2016) Mucosal integrity and sensitivity to acid in the proximal esophagus in patients with gastroesophageal reflux disease. Am J Physiol Gastrointest Liver Physiol 311: G117-G122.

33. Holtzer P (2015) Acid-sensing ion channels in gastrointestinal function. Neuropharmacol 94: 72-79.

34. Holtzer P (2011) Transient receptor (TRP) channels as drug targets for diseases of the digestive system. Pharmcol Therap 131: 142-170.

35. Holtzer P (2009) Acid-sensitive ion channels and receptors. Handb Ex Pharmacol 194: 283-332.

36. Gotley DC, Morgan AP, Ball D, Owen RW, Cooper MJ, et al. (1991) Composition of gastro-oesophagel refluxate. Gut 32: 1093-1099.

37. Hofmann AF, Mysels KJ (1992) Bile solubility and precipitation in vitro and in vivo: the role of conjugation, $\mathrm{pH}$, and $\mathrm{Ca} 2+$ ions. J Lipid Res 33(5): 617-626.

38. Nehra D1, Howell P, Williams CP, Pye JK, Beynon J (1999) Toxic bile acids in gastro-oesophageal reflux disease: influence of gastric acidity. Gut 44: 598-602.

39. Hershcovici T, Jha LK, Cui H, Powers J, Fass R (2011) Night-time intraoesophageal bile and acid: a comparison between gastro-esophageal reflux disease patients who failed and those who were treated successfully with a proton pump inhibitor. Aliment Pharmacol Ther 33(7): 837-844.

40. Ghatak S, Reveiller M, Toia L, Ivanov AI, Zhou Z, et al. (2016) Bile salts at low $\mathrm{pH}$ cause dilation of intercellular spaces in in vitro stratified primary esophageal cells, possibly by modulating Wnt signaling. J Gastrointest Surg 20: 500-509.

41. Chen X, Oshima T, Shan J, Fukui H, Watari J, et al. (2012) Bile salts dirupt human esophageal squamous epithelial barrier function by modulating tight junction proteins. Am J Physiol Gastrointest Liver Physiol 303: G199-G208.

42. Li WT, Luo QQ Wang B, Chen X, Yan XJ, et al. (2019) Bile acids induce visceral hypersensitivity via mucosal mast cell-t0-nociceptor signaling that involves the farnesoid X receptor/nerve growth factor/transient receptor potential vanilloid 1 axis. FASEB J 33(2): 2435-2450.

43. Vaezi MF, Richter JE (1996) Role of acid and duodenogastroesophageal reflux in gastroesophageal reflux disease. Gastroenterol 111(5): 11921199.

44. Tack J, Koek G, Demedts I, Sifrim D, Janssens J (2004) Gastroesophageal reflux disease poorly responsive to single-dose proton pump inhibitors in patients without Barrett's esophagus: acid reflux, bile reflux, or both. Am J Gastroenterol 99(6): 981-988.

45. Fitzgerald RC, Abdalla S, Onwuegbusi BA, Sirieix P, Saeed IT, et al. (2002) Inflammatory gradient in Barrett's oesophagus: implications for disease complications. Gut 51: 316-322.

46. Huo X, Zhang X, Yu C, Zhang Q, Cheng E, et al. (2014) In oesophageal 
squamous cells exposed to acidic bile salt medium, omeprazole inhibits IL-8 expression through effects on nuclear factor $\mathrm{kB}$ and activator protein-1. Gut 63(7): 1042-1052.

47. Kim JJ, Kim N Choi YJ (2016) Increased TRPV1 and PAR2 mRNA expression levels are associated only with the esophageal reflux symptoms but not with extrasophageal reflux symptoms. Mediine (Baltimore) 95(32): e4387.

48. Yoshida N, Kamada K, Tomatsuri N (2011) Non-erosive reflux disease and neurogenic inflammation: Assocation of circulating Substance P and Nerve Growth Factor levels with heartburn symptoms. Gastroenterol $140(5)$.

49. Shan J, Oshima T, Chen X, Fukui H, Watari J, et al. (2012) Trypsin impaired epithelial barrier function and induced IL-8 secration through basolateral PAR-2: a lesson from a stratified squamous epithelial model. Am J Physiol Gastrointest Liver Physiol 303(10): G1105-1112.

50. Bjorkman EV, Edebo A, Oltean M, Casselbrant A (2013) Esophageal barrier function and tight junction expression in healthy subjects and patients with gastroesophageal reflux disease: functionality of esophageal mucosa exposed to bile salt and trypsin in vitro. Scand J Gastroenterol 48(10): 1118-1126.

51. Kandulski A, Wex T, Mönkemüller K, Kuester D, Fry LC, et al. (2010) Proteinase-activated receptor- 2 in the pathogenesis of gastroesophageal reflux disease. Am J Gastroenterol 105(9): 1034-43.

52. Hunter J (1772) On the digestion of the Stomach after death. Philosh Trans 62: 447.

53. Pavy FW (1863) On the Immunity enjoyed by the Stomach from being digested by its own secretion during life. Philosh Trans 153: 161.

54. Schiff M (1898) Autodigestion of the Stomach after death and during life. Beitr Physiol 4: 405.

55. de Klug F (1907) Pourquoi les ferments protéolytiques ne digèrent-ils pas l'estomac et l'intestin sur le vivant. Arch internat physiol 5: 297.

56. Irvine JC, Hynd A (1913) Synthetical Aminoglucosides derived from d-glucosamine (Series). Chem Soc Trans 103: 41-56.

57. Levine PA, Lopez-Suarez J (1918) Mucins and Mucoids. J Biol Chem 36(1): 105-126.

58. Whitlow JE (1920) The protective role of gastric mucus against the proteolytic action of gastric secretion. Master's Thesis. Loyola University Medical School, USA

59. Bradley HC, Hodges M (1934) The effect of mucin and mucinoids on peptic digestion. J Lab Clin Med 20: 165.

60. Miller CO, Dunbar J (1933) Change in viscosity of mucin with pH. Proc Soc Exper Biol Med 30: 627.

61. Atkinson AJ (1932) Gastric mucin in the treatment of peptic ulcer. JAMA 98(14): 1153-1156.

62. Babkin BP, Komarov SA (1932) The influence of gastric mucus on peptic digestion. Can Med Assoc J 27: 463-469.

63. Hollander F, Stein J, Laubeer FU (1946) The consistency, opacity and columnar cell content of gastric mucus secreted under the influence of several mild irritants. Gastroenterol 6: 576-595.

64. Hollander F, Sonnenblick BP, Sober HA (1947) Experimental impairment of the gastric mucous barrier in dogs. J Natl Cancer Inst 7: 361.

65. Hollandeer F (1950) Secretion of gastric mucus in health and disease Bockus HL (eds.), Postgraduate Gastroenterology pp. 39-52.

66. Janowitz HD, Hollander F (1951) Some properties of cell-free gastric mucus. Fed Proc 10: 70.

67. Levey S, Sheinfeld S (1954) The inhibition of the proteolytic action of pepsin by sulfate containing polysaccharides. Gastroenterology 27: 625628.

68. Anderson W, Watt J (1959) Inhibition of peptic activity, protection against histamine ulceration in the guinea pig and combination with gastric mucin by an algal polyanion. J Pharm Pharmacal 11: 318.
69. Bianchi RG, Cook DL (1964) Anti peptic and anti-ulcerogenic properties of a synthetic sulfated polysaccharide (SN-263). Gastroenterology 47: 409-414.

70. Cook DL, Eich S, Cammarata PS (1963) Comparative pharmacology and chemistry of synthetic sulfated polysaccharides. Arch int Pharmacodyn 144: 1-19.

71. Cayer D, Raffin JM (1967) Effect of Depepsin (amylopectin sulfate) in the treatment of peptic ulcer. Ann NY Acad Sci 140: 744-746.

72. Ishimori A (1995) History of the Development of Sucralfate. In Sucralfate: From Basic Science to the Bedside. Daniel Hollander and GNJ Tytgat (eds.), Plenum Press, New York, pp. 35-44.

73. Ishimori A (1971) Mechanism of the Antipeptic Action of Anionic Carbohydrate and Its Clinical Application for the Treatment of Peptic Ulcer. Tohoku J Exp Med 103: 141-157.

74. Yamagata S, Ishimori A, Sato H, Okabe H, Ishihara K (1973) Clinical Evaluation of Pharmacotherapy for Peptic Ulcer with Antipepsin Agents by Double Blind Technique - Multicenter Clinical Study. Tohoku J Exp Med 110: 377-404.

75. Nitta Y, Masaya K, Kawa-saki-shi N (1969) Dissacharide polysulfate aluminium compound and method. US Patent 3: 432-489.

76. (1982) US Food and Drug Administration. Carafate (Sucralfate).

77.(1991) US Food and Drug Administration. Carafate (Sucralfate) Suspension.

78. (2019) Sucralfate.

79. Ishimori A (1981) Safety experience with sucralfate in Japan. J Clin Gastroenterol 3(Suppl2): 169-173.

80. Nakazawa S, Nagashima R Samloff IM (1981) Selective binding of sucralfate to gastric ulcer in man. Dig Dis Sci N S 26: 297-300.

81. Sasaki H, Hinohara Y, Tsunoda Y, Nagashima R (1983) Binding of sucralfate to duodenal ulcer in man. Scand J Gastroenterol 18(suppl 83): $13-14$

82. Nagashima R (1981) Mechanisms of action of sucralfate. J Clin Gastroenterol 3(Suppl 2): 117-127.

83. Kashimura K, Ozawa K (1999) Sucralfate Preparations. US Patent 5: $906-$ 968.

84. McGaughey GB, Gagne M, Rappe AK (1998) П-Stacking Interacitons alive and well in proteins. J Biol Chem 273(25): 15458-15463.

85. Mathews DR, Dahl NG (1995) Safety of sucralfate. in Sucralfate: From Basic Science to the Bedside. Daniel Hollander and GNJ Tytgat (eds.), Plenum Press, New York, pp. 215-223.

86. Morris GP (1995) Binding of sucralfate to mucosal surface. In Sucralfate: from basic science to the bedside. Daniel Hollander and GNJ Tygat (eds.), Plenum Press, New York.

87. Cohen MM, Bowdler R, Gervais P, Morris GP, Wang HR, et al. (1989) Sucralfate protection of human gastric mucosa against acute ethanol injury. Gastroenterol 96: 292-298.

88. Tasman-Jones C, Morrison G, Thomsen L, vanDerwee M (1989) Sucralfate interactions with gastric mucus. Am J Med 86(suppl6A): 5-9.

89. Masuelli L, Tumino G, Turriziani M, Modesti A, Bei R (2010) Topical use of sucralfate in epithelial wound healing: clinical evidence of molecular mechanisms of action. Rec Pat Inflamm Allergy Drug Disc 4: 25-36.

90. Konturek SJ, Brozozowski T, Bielanski W, Warzecha Z, Drozdowicz D (1989) Epidermal growth factor in the gastroprotective and ulcerhealing actions of sucralfate in rats. Am J Med 86(6A): 32-37.

91. Nexo E, Poulsen SS (1987) Does epidermal growth factor play a role in the action of sucralfate. Scand J Gastroenterol Suppl 127: 45-49.

92. Hollander D, Tytgat GNJ (1995) Sucralfate: From Basic Science to the Bedside. Daniel Hollander and GNJ Tytgat (eds.), Plenum Press, New York. 
93. Slomiany BL, Murty VL, Piotrowski J, Slomiany A (1989) Effect of antiulcer agents on the physiochemical properties of gastric mucus. Symp Soc Exp Biol 43: 179-191.

94. Slomiany BL, Laszewicz W, Murty VL, Kosmala M, Slomiany A (1985) Effect of sucralfate on the viscosity and retardation of hydrogen ion diffusion by gastric mucus glycoprotein. Comp Biochem Physiol C 82(2): 311-314.

95. Slomiany BL, Liu J, Slomiany A (1992) Modulation of gastric mucosa calcium channel activity by sucralfate. Biochem Int 28(6): 1125-1134.

96. Caspary WF (1995) Binding of bile salts by sucralfate. In Sucralfate: from basic science to the bedside. Daniel Hollander and GNJ Tygat (eds.), Plenum Press, New York.

97. Schweitzer EJ, Bass BL, Johnson LF, Harmon JW (1985) Siucralfate prevents experimental peptic esophagitis in rabbits. Gastroenterol 88: 611-619.

98. Louw JA, Young GO, Winter TA, Marks IN (1995) Sucralfate and Helicobacter Pylori. In Sucralfate: from basic science to the bedside. Daniel Hollander and GNJ Tygat (eds.), Plenum Press, New York.

99. Slomiany BL, Piotrowski J, Slomiany A (1992) Effect of sucralfate on the degradation of human gastric mucus by helicobacter pylori protease and lipases. Am J Gastroenterol 87(5): 595-599.

100. Tarnawski A, Hollander D, Stachura J, Mach T, Bogdal J (1987) Effect of sucralfate on the normal human gastric mucosa. Endoscopic histologic, and ultrastructural assessment. Scand J Gastroenterol Suppl 127: 111-123.

101. Tarnawski A, Hollander D, Krause WJ, Zipser RD, Stachura J, et al. (1986) Does sucralfate affect the normal gastric mucosa? Histologic, ultrastructural, and functional assessment in the rat. Gastroenterol 90(4): 893-905

102. France MM, Turner JR (2017) The mucosal barrier at a glance. J Cell Sci 130: 307-314.

103. Dixon J, Strugala V, Griffin SM, Welfare MR, Dettmar PW, et al. (2001) Esophageal mucin: an adherent mucus gel barrier is absent in the normal esophagus but present in columnar-lined Barrett's esophagus. Am J Gastroenterol 96(9): 2575-2583.

104. Lehr CM, Poelma FGJ, Hans E Junginger, Josef J Tukker (1991) An estimate of turnover time of intestinal mucus gel layer in the rat in situ loop. Intl J Pharmaceutics 70: 235-240.

105. Rubinstein A, Tirosh B (1994) Mucus gel thickness and turnover in the gastrointestinal tract of the rat: response to cholinergy stimulus and implication for mucoadhesion. Pharm Res 11(6): 794-799.

106. Johansson MEV (2012) Fast Renewal of the Distal Colonic Mucus Layers by the Surface Goblet Cells as Measured by In Vivo Labeling of Mucin Glycoproteins. PLoS ONE 7(7): e41009.

107. Kararli TT (1995) Comparison of the gastrointestinal anatomy, physiology and biochemistry of humans and commonly used laboratory animals. Biopharmaceut Drug Disp 16: 351-380.

108. Powell DW (1987) Ion and water transport in the intestine. In: TE Andreoli, SG Schultz (eds.), Physiology of Membrane Disorders $\left(2^{\text {nd }}\right.$ edn.), Plenum, New York, pp. 559-596.

109. Lang T, Hansson GC, Samuelsson T (2007) Gel-forming mucins appeared early in metazoan evolution. Proc Natl Acad Sci USA 104 16209-16214.

110. Atuma C, Strugala V, Allen A, Holm L (2001) The adherent gastrointestinal mucus gel layer: thickness and physical state in vivo. Am J Physiol Gastrointest Liver Physiol 280: G922-G929.

111. Johansson ME, Phillipson M, Petersson J, Velcich A, Holm L, et al. (2008) The inner of the two MUC2 mucin-dependent mucus layers in colon is devoid of bacteria. Proc Natl Acad Sci USA 105: 15064-15069.

112. van Putten JP, Strijbis K (2017) Transmembrane mucins: signaling receptors at the intersection of inflammation and cancer. J Innate
Immun 9: 281-299.

113. Aihara E, Engevik KA, Montrose MH (2017) Trefoil factor peptides and gastrointestinal function. Annu Rev Physiol 79:357-380.

114. Dignass A, Lynch-Devaney K, Kinbdon H et al. (1994) Trefoil Peptides Promote Epithelial Migration through a Transforming Growth Factor $\beta$ -independent Pathway. J Clin Invest 94(1): 376-383.

115. Iizuka M, Konno S (2011) Wound healing of intestinal epithelial cells. World J Gastroenterol 17(17): 2161-2171.

116. Wong WM, Playford RJ, Wright NA (2000) Peptide gene expression in gastrointestinal mucosal ulceration: ordered sequence or redundancy. Gut 46: 286-292.

117. Peitz U, Kouznetsova I, Wex T, Gebert I, Vieth M, et al. (2004) TFF3 expression at the esophagogastric junction is increased in gastoesophageal reflux disease (GERD). Peptides 25: 771-777.

118. Longman RJ, Douthwaite J, Sylvester PA, Poulsom R, Corfield AP, et al. (2000) Coordinated localization of mucins and trefoil peptides in the ulcer associated cell lineage and the gastrointestinal mucosa. Gut 47: 792-800.

119. Gum JR Jr, Hicks JW, Toribara NW, Siddiki B, Kim YS (1994) Molecular cloning of human intestinal mucin (MUC2) cDNA. Identification of the amino terminus and overall sequence similarity to pre-pro-von Willibrand factor. J Biol Chem 269: 2440-2446.

120. van Roon AH, Mayne GC, Wijnhoven BP, Watson DI, Leong MP, et al. (2008) Impact of gastro-esophageal reflux on mucin mRNA expression in the esophageal mucosa. J Gastrointest Surg 12: 1331-1340.

121. Carraway KL, Theodoropoulos G, Kozloski GA, Carraway CAC (2009) Muc4/MUC4 functions and regulation in cancer. Future Oncol 5(10): 1631-1640.

122. Hollander D, Tarnawski A, Gergely H, Zipser RD (1984) Sucralfate protection of the gastric mucosa against ethanol-induced injury: a prostaglandin-meidated process. Scand J Gastroenterol 19: 97-102.

123. Hollander D, Tarnawski A, Krause WJ, Gergely H (1985) The protective effect of sucralfate against alcohol-induced gastric mucosal injury in the rat. Macroscopic, histologic, ultrastructural and functional time sequence analysis. Gastroenterol 88: 366-374.

124. Cohen MM, Bowdler R, Gervais P, Morris GP, Wang HR (1989) Sucralfate protection of human gastric mucosa against acute ethanol injury. Gastroenterol 96: 292-298.

125. Szabo S, Brown A (1987) Prevention of ethanol-induced vascular injury and gastric mucosal lesions by sucralfate and its components: Possible role of endogenous sulfhydryls. Proc Soc Exp Biol Med 185: 493-497.

126. Bianchi Porro G, Hollander D (1989) Treatment of Digestive Disease with Sucralfate. New York, Raven Press.

127. Bighley L, Giesing D (1981) Mechanism of action studies of sucralfate, in Caspary W (ed): Duodenal Ulcer, Gastric Ulcer: Sucralfate, a New Treatment Concept. Munich, Urban \& Schwarzenberg pp. 3-12.

128. Longman RJ, Douthwaite J, Sylvester PA, Poulsom R, Corfield AP, et al. (2000) Coordinated localization of mucins and trefoil peptides in the ulcer associated cell lineage and the gastrointestinal mucosa. Gut 47: 792-800.

129. Carraway KL, Ramsauer VP, Haq B, Carothers Carraway CA (2003) Cell signaling through membrane mucins. BioEssays 25: 66-71.

130. Cone RA (2009) Barrier properties of mucus. Adv Drug Deliv Rev 61: 75-85.

131. Pelaseyed T, Zäch M, Petersson AC, Svensson F, Johansson DG, et al. (2013) Unfolding dynamics of the mucin SEA domain probed by force spectroscopy suggest that it acts as a cell-protective device. FEBS J 280: 1491-1501.

132. Martinez SD, Malagon IB, Garewal HS, Cui H, Fass R (2003) Nonerosive reflux disease (NERD)-acid reflux and symptom patterns. Aliment 
Pharmacol Ther 17: 537-545.

133. Shiovitz TM, Bain EE, McCann DJ, Skolnick P, Laughren T, et al. (2016) Mitigating the Effects of Nonadherence in Clinical Trials. The Journal of Clinical Pharmacology 56(9): 1151-1164.

134. Hetzel DJ, Dent J, Reed WD, Narielvala FM, Mackinnon M, et al. (1988) Healing and relapse of severe peptic esophagitis after treatment with omeprazole. Gastroenterology 95: 903-912.

135. Khan M, Santana J, Donnellan C, Preston C, Moayyedi P (2007) Medical treatments in the short term management of reflux oesophagitis. Cochrane Database Syst Rev 2: CD003244.

136. Khan M, Santana J, Donnellan C, Preston C, Moayyedi P (2007) Medical treatments in the short term management of reflux oesophagitis. Cochrane Database of Systematic Reviews 2: CD003244.

137. Stoker DL, Williams JG, Dewar EP (1988) The pH and concentration of bile in the oesophagus. Gut 29: A728-A729.

138. Kedika RR, Souza RF, Spechler SJ (2009) Potential anti-inflammatory effects of proton pump inhibitors: a review and discussion of the clinical implications. Dig Dis Sci 54: 2312-2317.

139. Modlin IM, Hunt RH, Malfertheiner P, Moayyedi P, Quigley EM, et al. (2009) Diagnosis and management of non-erosive reflux disease- the
Vevey NERD Consensus Group. Digestion 80(2): 74-88.

140. Sun D, Wang X, Gai Z, Song X, Jia X, et al. (2015) Bile acids but not acidic acids induce Barrett's esophagus. Int J Clin Esp Phathol 8(2): 13841392.

141. Dulai GS, Guha S, Kahn KL, Gornbein J, Weinstein WM (2002) Preoperative prevalence of Barrett's esophagus in esophageal adenocarcinoma: a systematic review. Gastroenterology 122(1): 2633.

142. Souza RF (2016) From reflux esophagitis to esophageal adenocarcinoma. Dig Dis 34(5): 483-490.

143. Dunbar KB, Agoston AT, Odze RD, Huo X, Pham TH, et al. (2016) Association of Acute Gastroesophageal Reflux Disease With Esophageal Histologic Changes. JAMA 315: 2104-2112.

144. Souza RF, Bayeh L, Spechler SJ, Tambar UK, Bruick RK (2017) A new paradigm for GERD pathogenesis. Not acid injury, but cytokinemediated inflammation driven by HIF-2a: a potential role for targeting HIF-2A to prevent and treat reflex espohagitis. Curr Opin Pharmacol 37: 93-99.

145. Yoshida N, Terao N, Nagashima R (1979) Sucralfate, a basic aluminum salt of sucrose sulfate. IV. Interaction with enzyme pepsin. Arzneim ForschiDrug Res 30(1): 78-80. 